\title{
Amyloid-like aggregating proteins cause lysosomal defects in neurons via gain-of-function toxicity
}

\author{
Irene Riera-Tur ${ }^{1,2, *} \mathbb{D}$, Tillman Schäfer ${ }^{3, *} \mathbb{C}$, Daniel Hornburg ${ }^{4,5, *} \mathbb{D}$, Archana Mishra ${ }^{1}$, Miguel da Silva Padilha ${ }^{1,2}$, \\ Lorena Fernández-Mosquera ${ }^{6}$, Dennis Feigenbutz ${ }^{1,2}$, Patrick Auer ${ }^{1,2}$, Matthias Mann ${ }^{4} \mathbb{D}$, Wolfgang Baumeister ${ }^{3}$,

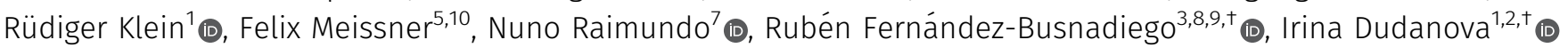

The autophagy-lysosomal pathway is impaired in many neurodegenerative diseases characterized by protein aggregation, but the link between aggregation and lysosomal dysfunction remains poorly understood. Here, we combine cryo-electron tomography, proteomics, and cell biology studies to investigate the effects of protein aggregates in primary neurons. We use artificial amyloid-like $\beta$-sheet proteins ( $\beta$ proteins) to focus on the gain-of-function aspect of aggregation. These proteins form fibrillar aggregates and cause neurotoxicity. We show that late stages of autophagy are impaired by the aggregates, resulting in lysosomal alterations reminiscent of lysosomal storage disorders. Mechanistically, $\beta$ proteins interact with and sequester AP-3 $\mu 1$, a subunit of the AP- 3 adaptor complex involved in protein trafficking to lysosomal organelles. This leads to destabilization of the AP-3 complex, missorting of AP-3 cargo, and lysosomal defects. Restoring AP-3 $\mu 1$ expression ameliorates neurotoxicity caused by $\beta$ proteins. Altogether, our results highlight the link between protein aggregation, lysosomal impairments, and neurotoxicity.

DOI 10.26508/lsa.202101185 | Received 5 August 2021 | Revised 2 December 2021 | Accepted 3 December 2021 | Published online 21 December 2021

\section{Introduction}

The autophagy-lysosomal system is a major cellular degradation pathway for long-lived proteins, macromolecular complexes, and damaged organelles (Settembre et al, 2013; Finkbeiner, 2020). Defects in this system cause a number of severe disorders known as lysosomal storage diseases, often characterized by early-onset neurodegeneration (Fraldi et al, 2016; Platt et al, 2018). In addition, lysosomal function is compromised in many age-related neurodegenerative disorders, such as amyotrophic lateral sclerosis, Alzheimer's, Parkinson's, and Huntington's disease (Abeliovich \& Gitler, 2016; Fraldi et al, 2016; Taylor et al, 2016; Wang et al, 2018; Finkbeiner, 2020; Nixon, 2020). Another convergent feature of late-onset neurodegenerative diseases is protein misfolding and aggregation, which leads to accumulation of toxic protein species and neuronal demise (Soto \& Pritzkow, 2018). As autophagy represents an important pathway for removal of aggregated proteins, dysfunction of the autophagy-lysosomal system facilitates the build-up of aggregates (Wang et al, 2018; Finkbeiner, 2020). Conversely, aggregating proteins themselves might directly interfere with the normal function of the autophagy-lysosomal machinery (Cuervo et al, 2004; Winslow et al, 2010; Wong \& Holzbaur, 2014). However, until now the mechanistic link between aggregation and lysosomal impairments is not completely understood.

One difficulty in studying the role of protein aggregation in cellular dysfunction is the overlap of gain- and loss-of-function effects resulting from protein misfolding. On one hand, reduction in the cellular pool of the correctly folded form of an aggregating protein results in a partial loss of its native function. At the same time, the misfolded conformation of the protein can engage in aberrant interactions with cellular membranes and with other proteins, causing gain-of-function toxicity (Olzscha et al, 2011; Winner et al, 2011; Kim et al, 2016; Yang \& Hu, 2016; Bauerlein et al, 2017; Chiti \& Dobson, 2017). These loss- and gain-of-function effects occur in parallel and are difficult to disentangle, especially because the native functions of many aggregating proteins are still poorly understood (Winklhofer et al, 2008; Saudou \& Humbert, 2016;

\footnotetext{
${ }^{1}$ Department of Molecules-Signaling-Development, Max Planck Institute of Neurobiology, Martinsried, Germany ${ }^{2}$ Molecular Neurodegeneration Group, Max Planck Institute of Neurobiology, Martinsried, Germany ${ }^{3}$ Department of Molecular Structural Biology, Max Planck Institute of Biochemistry, Martinsried, Germany ${ }^{4}$ Department of Proteomics and Signal Transduction, Max Planck Institute of Biochemistry, Martinsried, Germany ${ }^{5}$ Experimental Systems Immunology Group, Max Planck Institute of Biochemistry, Martinsried, Germany ${ }^{6}$ The William Harvey Research Institute, Barts and The London School of Medicine and Dentistry, Queen Mary University of London, London, UK ${ }^{7}$ Department of Cellular and Molecular Physiology, Penn State College of Medicine, Hershey, PA, USA ${ }^{8}$ Institute of Neuropathology, University Medical Center Goettingen, Goettingen, Germany ${ }^{9}$ Cluster of Excellence "Multiscale Bioimaging: from Molecular Machines to Networks of Excitable Cells" (MBExC), University of Goettingen, Goettingen, Germany ${ }^{10}$ Department of Systems Immunology and Proteomics, Institute of Innate Immunity, Medical Faculty, University of Bonn, Bonn, Germany
}

Correspondence: idudanova@neuro.mpg.de; ruben.fernandezbusnadiego@med.uni-goettingen.de

Tillman Schäfer's present address is Cryo-EM Facility, Max Planck Institute of Biochemistry, Martinsried, Germany.

Daniel Hornburg's present address is Department of Genetics, Stanford University School of Medicine, Stanford, CA, USA

*Irene Riera-Tur, Tillman Schäfer, and Daniel Hornburg contributed equally to this work.

tRubén Fernández-Busnadiego and Irina Dudanova contributed equally to this work. 
Brothers et al, 2018). To overcome this challenge, here we take advantage of artificial proteins (hereafter $\beta$ proteins), which have been rationally designed to form antiparallel $\beta$-sheets because of an alternating pattern of polar and non-polar amino acid residues (West et al, 1999). Antiparallel $\beta$-sheet structure is an important general property of natural aggregating proteins, as demonstrated for $A \beta$, polyQ proteins, pathological tau, and $\alpha$-synuclein (Chiti \& Dobson, 2017; Hartl, 2017). $\beta$ proteins spontaneously assemble into amyloid-like fibrils in vitro (West et al, 1999). When expressed in cells, $\beta$ proteins form inclusions and compromise cellular viability (Olzscha et al, 2011; Woerner et al, 2016; Vincenz-Donnelly et al, 2018; Frottin et al, 2019). Importantly, although being structurally similar to natural amyloids, $\beta$ proteins do not possess any biological function, and therefore provide an excellent tool to investigate toxic gain-of-function effects of aggregation in the absence of any loss-of-function phenomena.

In this study, we use a combination of cryo-electron tomography (cryo-ET), proteomics, and cell-biological approaches to study the impact of $\beta$ proteins on primary neurons. We find that $\beta$ protein aggregation impairs autophagy, leads to accumulation of enlarged lysosomes with undigested cargo, and induces neurotoxicity. Our data suggest that these defects are mediated, at least in part, by the sequestration of a subunit of the AP-3 adaptor complex within the aggregates. Taken together, our findings link lysosomal impairments to toxic gain-of-function of protein aggregates.

\section{Results}

\section{$\beta$ protein aggregation causes toxicity in primary neurons}

To investigate the effects of $\beta$ protein aggregation in neurons, we used two $\beta$ proteins, $\beta 4$ and $\beta 23$, which differ in primary amino acid sequence, but adopt similar $\beta$-sheet structures (West et al, 1999). The proteins were tagged with a myc epitope and fused to mCherry ( $\beta 4$ mCherry and $\beta 23$-mCherry). We expressed $\beta$ proteins in dissociated murine cortical cultures using transfection or lentiviral transduction (see Table S1 for a summary of experimental conditions). Upon transfection of $\beta 4$-mCherry and $\beta 23$-mCherry, we observed formation of abundant cytoplasmic aggregates of irregular shape (Fig 1A and B). To assess whether the presence of $\beta$ proteins caused toxicity, we stained transfected cultures for the apoptotic marker cleaved caspase-3 (Fig 1C). Both $\beta 4$-mCherry and $\beta 23$-mCherry induced a significant increase in the number of cleaved caspase-3-positive cells at DIV 10+3 (Fig 1D). We observed similar results with lentivirally transduced neurons, where both $\beta 4$-mCherry and $\beta 23$-mCherry aggregated and accumulated in the insoluble fraction from DIV 10+4 (Fig S1A-D). Significant toxicity was observed for both $\beta$ proteins from DIV $10+6$ onwards, corresponding to appearance of abundant aggregates (Fig S1E).

We further assessed dendritic complexity, as it can be affected by pathological aggregates (May et al, 2014). These experiments were performed on transfected hippocampal neurons because of their uniform morphology. Sholl analysis revealed a significant reduction in dendritic complexity in neurons transfected with either $\beta 4$-mCherry or $\beta 23$-mCherry (Fig $1 \mathrm{E}$ and F). Altogether, these data indicate that $\beta$ proteins aggregate and cause toxicity in primary neurons.

\section{Ultrastructure of neuronal $\beta$ protein aggregates}

We used cryo-ET to explore the ultrastructure of $\beta$ protein aggregates and their potentially toxic cellular interactions in neurons. This technique allows investigating the structure of protein aggregates and their impact on the cellular milieu in close-to-native conditions at molecular resolution (Bauerlein et al, 2017; Wagner et al, 2017; Gruber et al, 2018; Guo et al, 2018; Trinkaus et al, 2021). Primary cortical neurons were grown on electron microscopy (EM) grids, transfected with $\beta$ proteins, and vitrified by plunge-freezing. Cryo-correlative microscopy allowed targeting the aggregates for cryo-focused ion beam (cryo-FIB) milling (Rigort et al, 2012) and subsequent cryo-ET using a Volta phase plate (Danev et al, 2014) (Fig S2A-F).

Analysis of cryo-electron tomograms revealed that all $\beta$ protein aggregates displayed fibrillar morphology (for numbers of analyzed aggregates, see Table S2) and consisted of an apparently disordered network of very thin fibrils (Fig 2A-D). The fibril diameters were similar for both $\beta$ proteins ( $\beta 4$-mCherry, $4.1 \pm 1.6 \mathrm{~nm} ; \beta 23-$ mCherry, $3.6 \pm 1.1 \mathrm{~nm} ; \mathrm{n}=30$ fibrils in both cases; unpaired t test, $\mathrm{n}$. s.) (Fig 2E). The fibrils were highly curved and branched, similar to those observed in vitro (Olzscha et al, 2011). The fibrillar network encapsulated additional electron-dense structures that may correspond to cellular proteins sequestered by the aggregates (Olzscha et al, 2011; Woerner et al, 2016), such as ribosomes (Fig 2B). No substantial differences were observed between neuronal aggregates of $\beta 4$-mCherry and $\beta 23$-mCherry, or between aggregates found in neurons and in HeLa cells (Figs 2 and S3 and Table S2).

$\beta$ protein aggregates were often found in direct contact with cellular membranes, especially those of the ER (Figs 2, S3, and S4F). In some cases, ER tubes surrounded the aggregate periphery and tunnelled through its interior (Fig S4F), similar to previous observations for polyQ, $\alpha$-Synuclein and heat-shock induced aggregates (Bauerlein et al, 2017; Wagner et al, 2017; Gruber et al, 2018; Trinkaus et al, 2021). However, in contrast to polyQ fibrils (Bauerlein et al, 2017), $\beta$ protein fibrils did not appear to deform cellular membranes (Figs $2 \mathrm{C}$ and $\mathrm{S} 3 \mathrm{~A}$ ). The ER around the aggregates often engaged in membrane contact sites with mitochondria (Figs 2D and S3B), as observed for stress-induced and polyQ aggregates (Zhou et al, 2014; Gruber et al, 2018). Thus, despite the distinct characteristics of aggregates formed by different proteins, $\beta$ protein aggregates reproduced some features of natural amyloids.

\section{$\beta$ protein expression leads to defects of lysosomal morphology}

Besides the presence of aggregates, the most striking ultrastructural feature of $\beta$ protein-expressing neurons was the accumulation of large endo-lysosomal organelles (Figs 3 and S4D-I). In control cells, a variety of endo-lysosomes was observed, including tubular early endosomes, multivesicular bodies, and autolysosomes containing membranous cargo (Figs $3 \mathrm{~A}$ and $\mathrm{B}$ and $\mathrm{S} 4 \mathrm{~A}-\mathrm{C}$ ). Although all those species were also found in $\beta$ protein-expressing cells, large ( $>1 \mu \mathrm{m}$ in diameter) cargo-loaded autolysosomes were enriched. No $\beta$ protein aggregates were observed within these organelles in tomograms or lamella overview images (for numbers of analyzed lysosomes, see Table S2). Instead, autolysosomes often contained extensive stacks of parallel membranes and smaller 
A

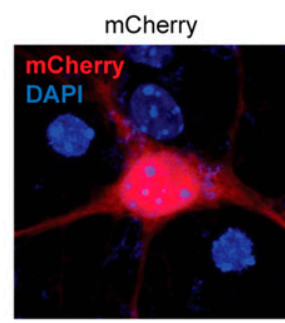

C
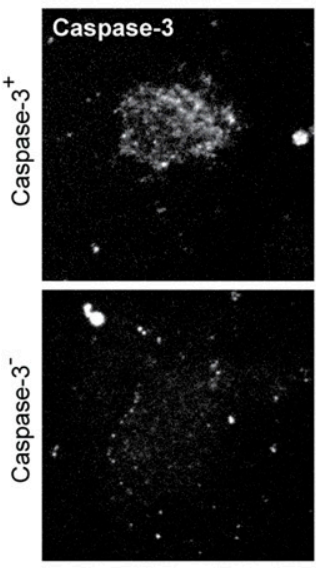

$\mathbf{E}$
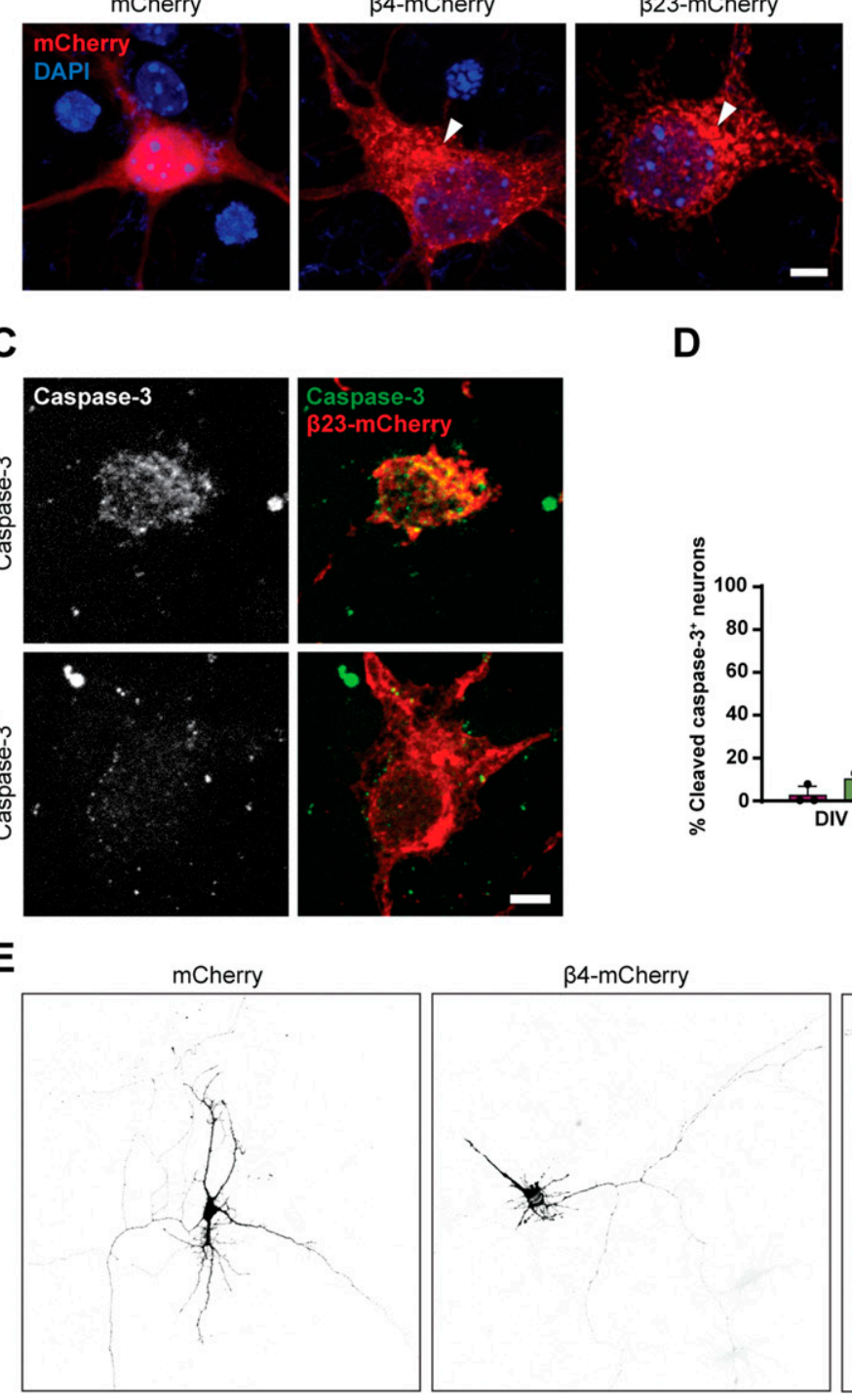

B

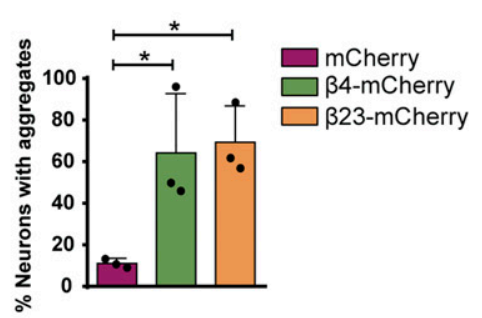

D

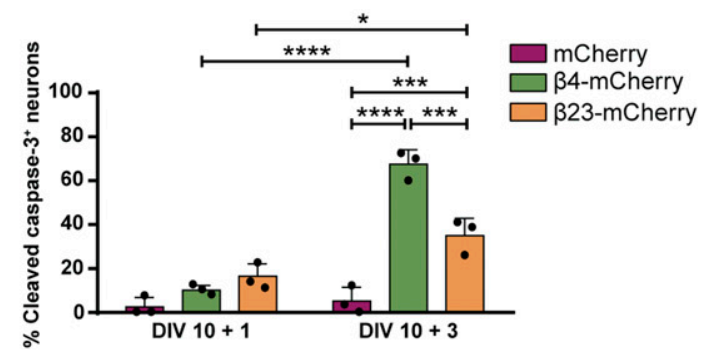

$\mathbf{F}$
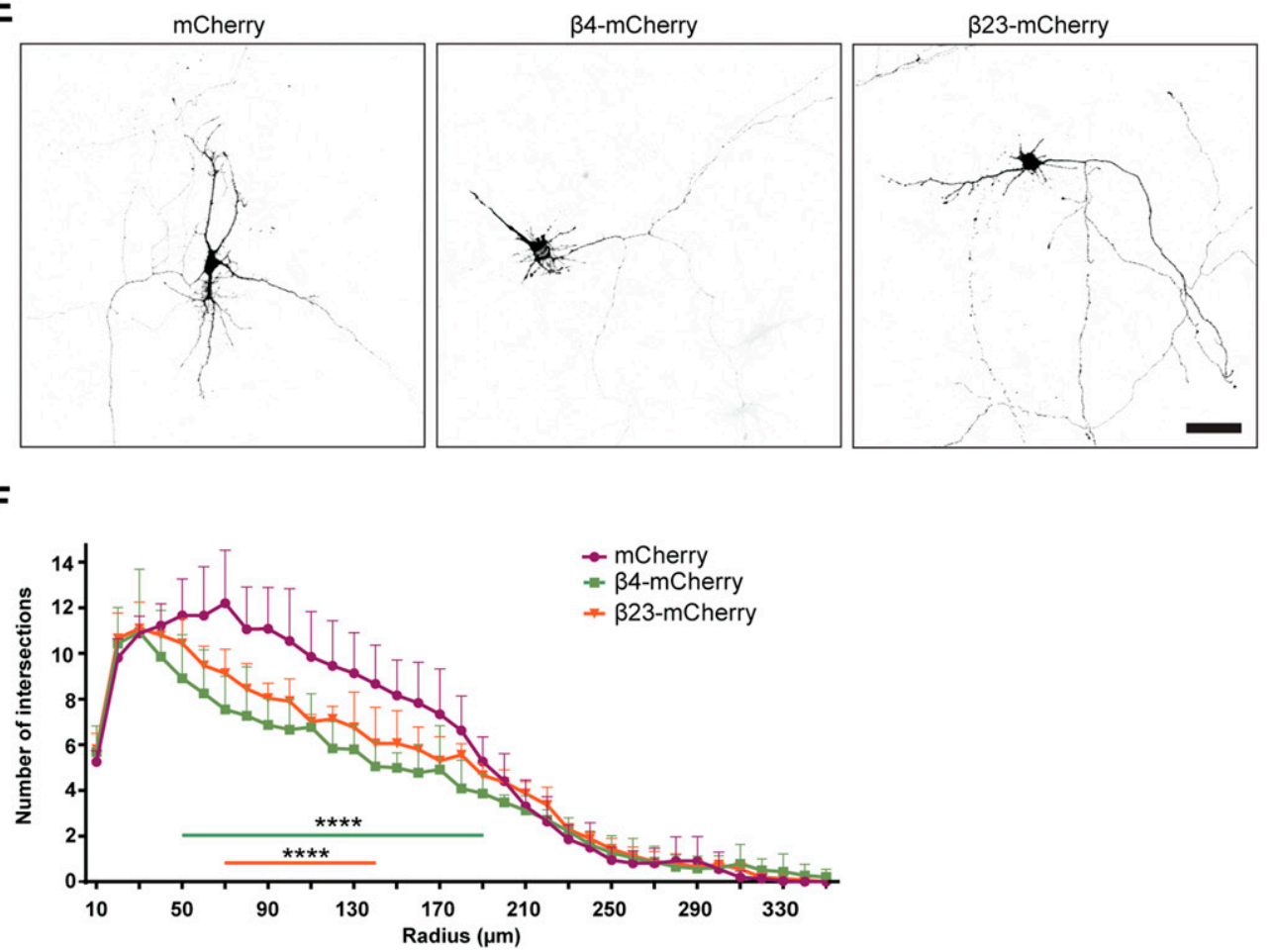

Figure 1. $\quad \beta$ proteins aggregate and cause toxicity in transfected primary neurons.

(A) Transfected cortical neurons at DIV $10+1$. Arrowheads point to $\beta$ protein aggregates. (B) Percentage of transfected neurons bearing aggregates at DIV $10+1$ ( $n=3$ independent experiments, $25-45$ cells/condition/experiment; one-way ANOVA with Dunnett's post hoc test). (C) Examples of DIV 10+1 $\beta 23-m$ Cherry neurons positive (top) and negative (bottom) for cleaved caspase-3. (D) Percentage of transfected neurons positive for cleaved caspase-3 ( $\mathrm{n}=3$ independent experiments, $25-45$ cells/ condition/experiment; two-way ANOVA with Tukey's post hoc test). (E) Examples of DIV 10+2 primary hippocampal neurons transfected with mCherry (left), $\beta 4$-mCherry (middle), or $\beta 23$-mCherry (right). Images are colour-inverted with mCherry fluorescence shown in black. Note that the $\beta$ protein cells have fewer primary dendrites. (F) Sholl analysis reveals reduced dendritic complexity in the presence of $\beta$ proteins ( $n=3$ independent experiments, 10-30 cells/condition/experiment; two-way ANOVA with Tukey's post hoc test). Scale bars, $5 \mu \mathrm{m}$ in (A and C); $50 \mu \mathrm{m}$ in (E). Data information: Data are presented as mean \pm SD. ${ }^{*} P<0.05 ;{ }^{* * * P<0.001 ;}{ }^{* * * * P<0.0001 .}$ 

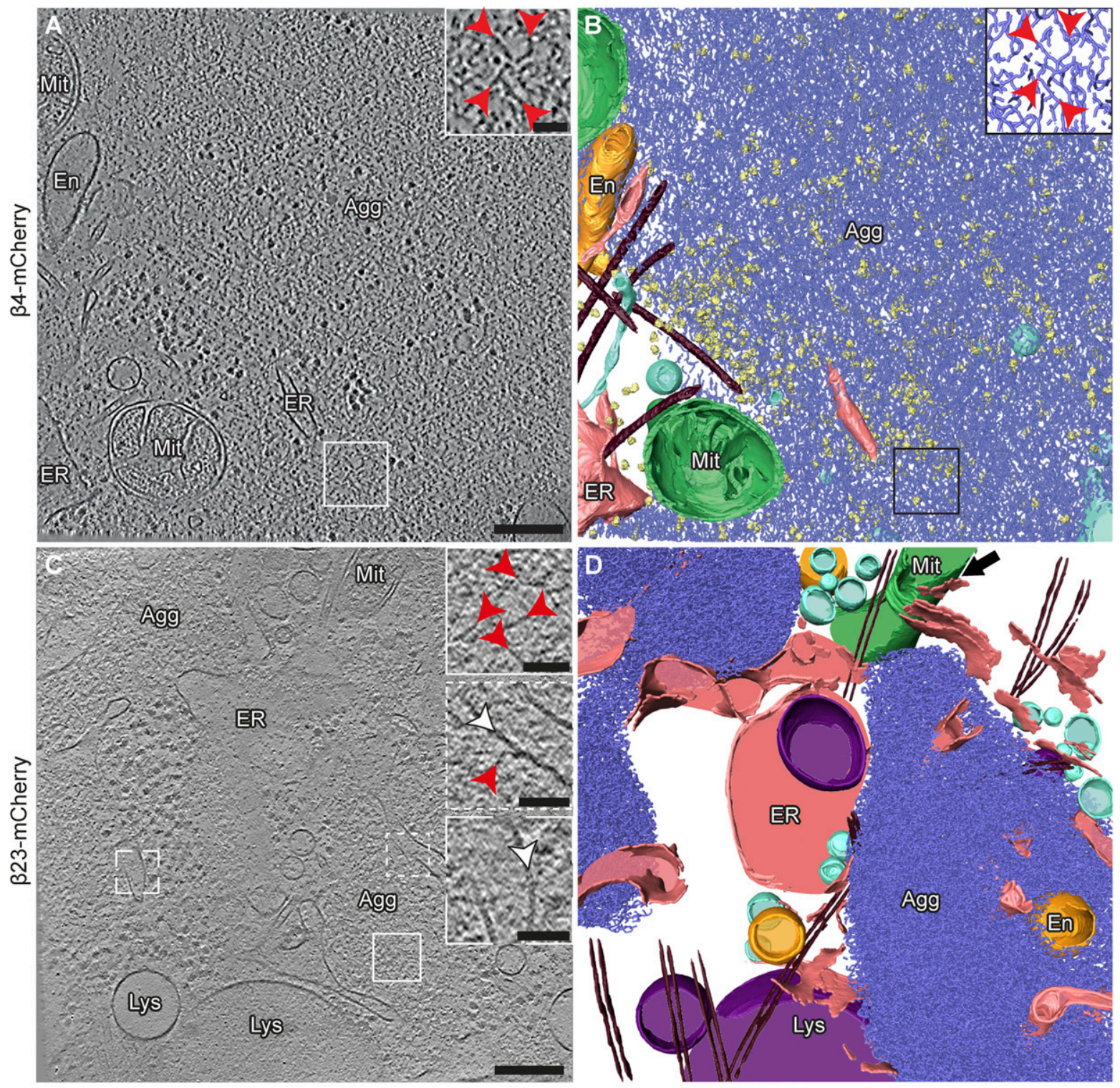

$E$

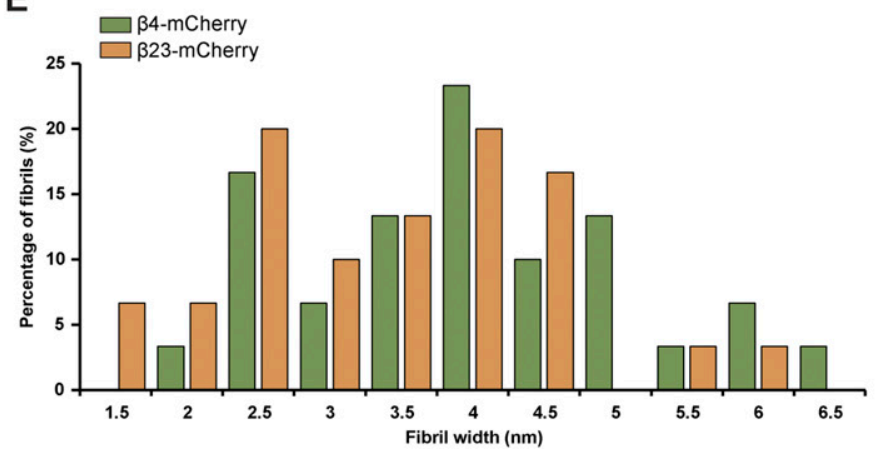

Figure 2. Ultrastructure of $\beta$ protein aggregates in primary neurons.

(A) Tomographic slice of a $\beta 4$-mCherry aggregate in transfected DIV 6+1 cortical neurons. (B) 3D rendering of the tomogram shown in (A). (C) Tomographic slice of two $\beta 23$-mCherry aggregates in neurons. (D) $3 \mathrm{D}$ rendering of the tomogram shown in (C). The areas marked by the boxes are magnified in the insets. Red arrowheads point to $\beta$ protein fibrils. White arrowheads point to intracellular membranes. Note that intracellular membranes in contact with $\beta$ protein fibrils (middle inset in C) are not deformed and do not differ from membranes that are not in direct contact with aggregates (lower inset in C). Agg, $\beta$ protein aggregate; En, endosome; ER, endoplasmic reticulum; Lys, lysosome; Mit, mitochondrion. Black arrow in (D) indicates ER - mitochondria contact site. $\beta$ protein fibrils, blue; mitochondria, green; ER membranes, salmon; endosome, gold; vesicles, cyan; ribosomes, yellow; microtubules, brown. (E) Histogram of $\beta 4$-mCherry and $\beta 23$-mCherry fibril diameters ( $n=30 \beta 4$-mCherry fibrils and 30 $\beta 23$-mCherry fibrils, from three tomograms each). Scale bars in (A, C), 200 and $50 \mathrm{~nm}$ (insets). 

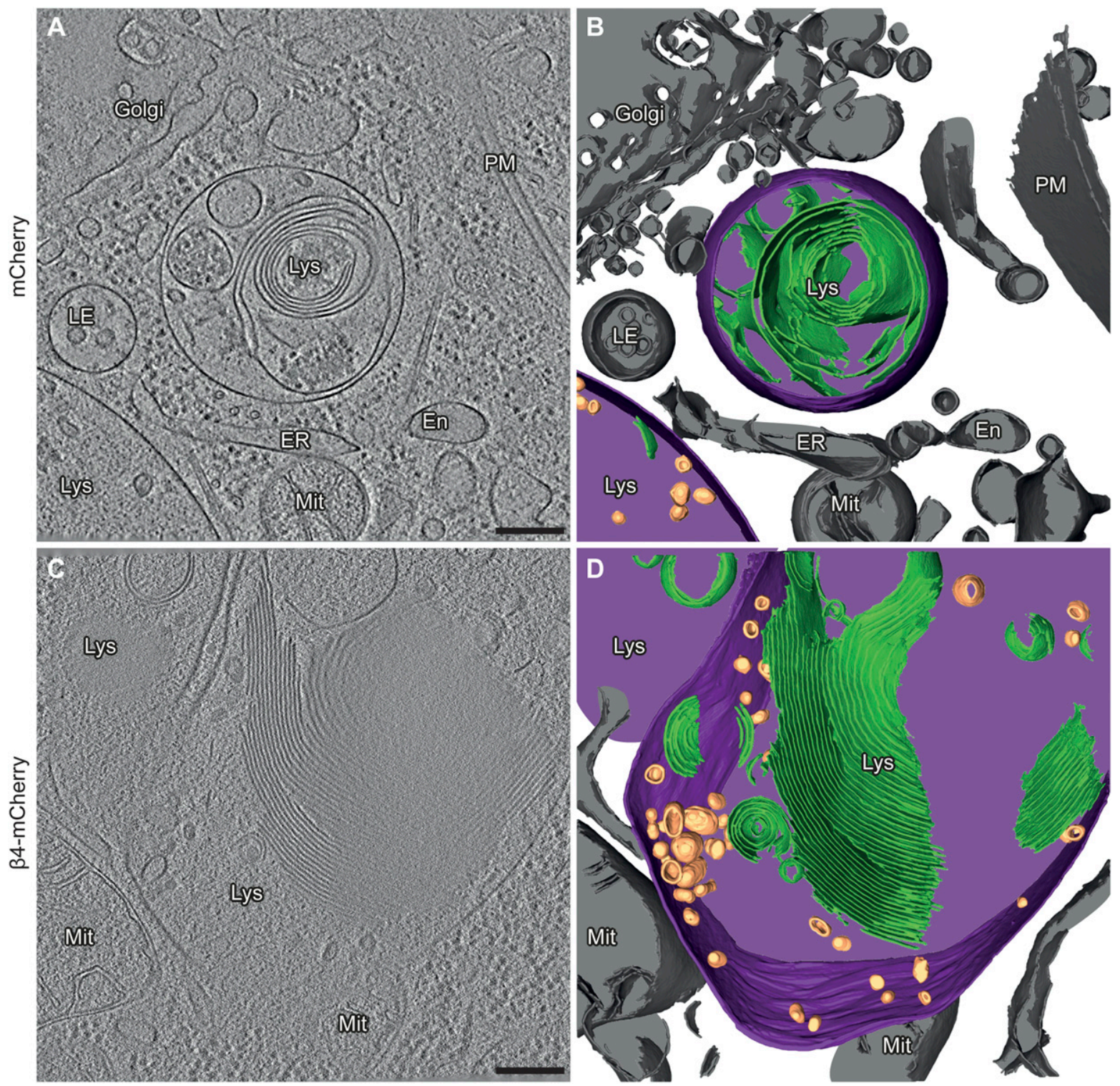

Figure 3. Aberrant lysosomal ultrastructure in $\beta$ protein-expressing neurons.

(A) Example of a lysosome in a tomogram from a DIV 6+1 cortical neuron transfected with mCherry. (B) 3D rendering of the tomogram shown in (A). (C) Example of a lysosome in a neuron transfected with $\beta 4$-mCherry. Note the presence of abundant membrane stacks and electron-dense material within the lysosome. (D) 3D rendering of the tomogram shown (C). En, endosome; ER, endoplasmic reticulum; LE, late endosome; Lys, lysosome; Mit, mitochondrion; PM, plasma membrane. Lysosomal membrane, purple; membrane stacks within the lysosomes, green; intraluminal vesicles, gold; other cellular membranes, grey. For additional examples see Fig S4. Scale bars in (A, C), $200 \mathrm{~nm}$.

vesicles, together with an electron-dense lumen suggestive of a high protein concentration (Figs $3 \mathrm{C}$ and D and S4D and H). Interestingly, similar structures were reported in Alzheimer's disease (Nixon et al, 2005; Gowrishankar et al, 2015), in Parkinson's disease, and other synucleinopathies (Crews et al, 2010; Dehay et al, 2012; Usenovic et al, 2012) and in conditions of impaired lysosomal degradation (Abraham et al, 1968; Spaet et al, 1983; Fernandez-Mosquera et al, 2019).

Consistently with cryo-ET, light microscopy experiments with LysoTracker-loaded neurons showed that $\beta$ protein expression led to an increase in lysosomal size (Fig 4A and B). Compared with mCherry cells, lysosomes with a diameter larger than $1 \mu \mathrm{m}$ were 3.5-fold more abundant in both $\beta 4$-mCherry and $\beta 23$-mcherry cells. However, the total number of LysoTracker-positive puncta per cell was reduced (Fig 4C). In agreement with cryo-ET findings, no significant colocalization was observed between $\beta$ protein aggregates and LysoTracker-positive organelles (Fig 4A and D). In summary, our cryo-ET and light microscopy data show that $\beta$ protein aggregation leads to the accumulation of enlarged, cargorich autolysosomes, although the aggregates themselves do not appear to build up inside these organelles. This is compatible with a scenario in which autophagic cargo is successfully delivered to lysosomes, but lysosomal degradation is defective. 
A
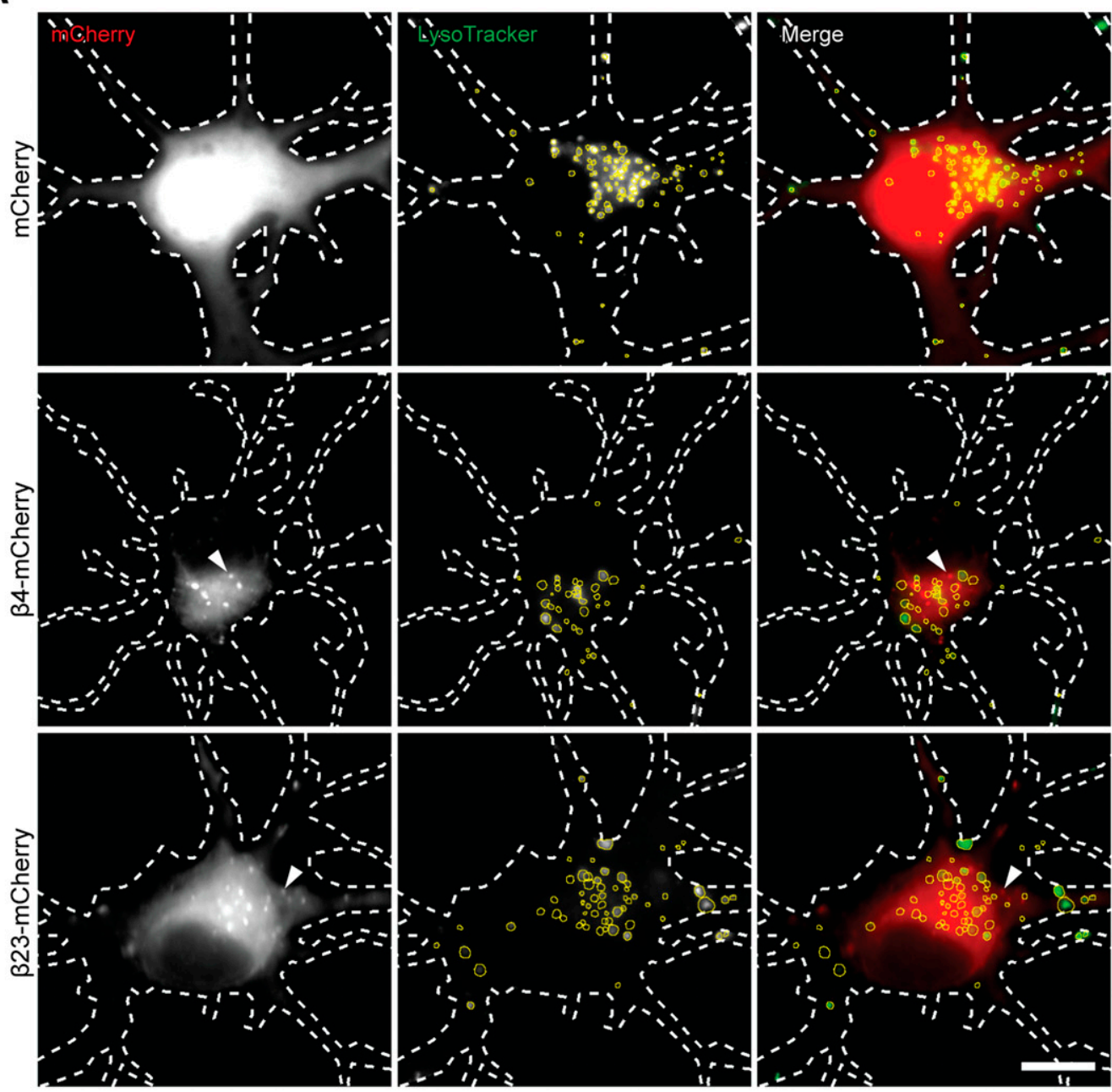

B

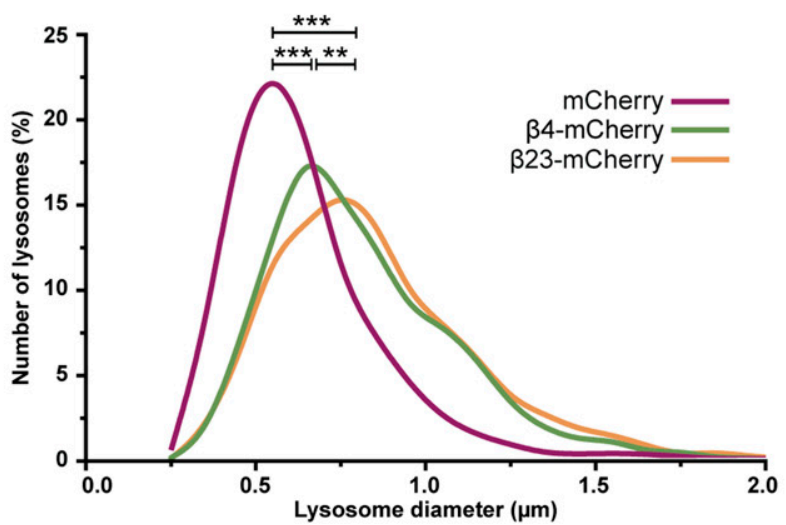

C
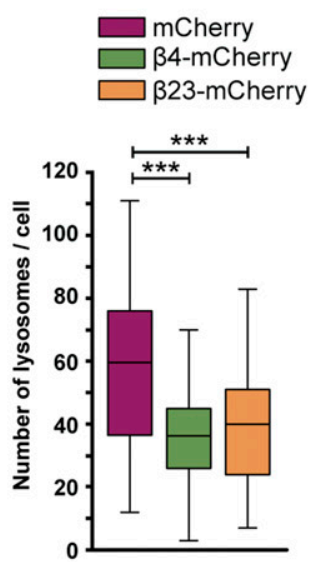

D

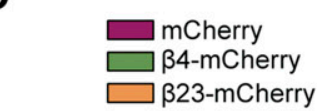

Figure 4. Defects of lysosomal morphology in the presence of $\beta$ proteins.

(A) Fluorescence images of DIV 6+1 primary cortical neurons transfected with mCherry (top), $\beta 4$-mCherry (middle), or $\beta 23$-mCherry (bottom) and incubated with LysoTracker Green. White dashed lines show the contours of the neurons. Arrowheads point to $\beta$ protein aggregates. Yellow circles outline lysosomes. (B) Distribution of the lysosomal size in control and $\beta$ protein-expressing neurons (mCherry, $\mathrm{n}=2,148$ lysosomes from 36 cells; $\beta 4$-mCherry, $\mathrm{n}=1,595$ lysosomes from 44 cells; $\beta 23$-mCherry, $\mathrm{n}=1,838$ lysosomes from 46 cells; from four independent experiments; two-tailed Mann-Whitney test). (C) Box plot showing the number of lysosomes per neuron ( $\mathrm{mCherry}, \mathrm{n}=36 \mathrm{cells} ; \beta 4-\mathrm{mCherry}, \mathrm{n}=44$ cells; $\beta 23$ - $\mathrm{mCherry}, \mathrm{n}=$ 46 cells; from four independent experiments; two-tailed Mann-Whitney test). (D) Quantification of Person's correlation coefficient between the mCherry and LysoTracker signal ( $n=36$ mCherry cells, $39 \beta 4$-mCherry cells, $36 \beta 23$-mCherry cells; one-way ANOVA with Tukey's post hoc test). Scale bar in (A), $10 \mu \mathrm{m}$. Data information: Data in (C) are presented as box plots with whiskers indicating minimal and maximal values. Data in (D) are presented as mean \pm SD. ${ }^{\star \star} P<0.01$; ${ }^{\star \star \star} P<0.001$; n.S., not significant. 


\section{$\beta$ proteins impair the autophagy-lysosomal pathway}

To assess possible dysfunctions of the autophagy-lysosomal pathway, we estimated autophagic flux by monitoring LC3-II, an autophagy-related protein that is itself degraded by lysosomes. First, we quantified LC3-II turnover in $\beta 23$-mCherry-transfected HeLa cells (Fig S5A) in the presence and absence of $50 \mu \mathrm{M}$ chloroquine, which blocks lysosomal degradation (Poole \& Ohkuma, 1981; Mauthe et al, 2018). In control mCherry cells, application of chloroquine resulted in a significant, twofold increase in LC3-II, whereas no significant accumulation of LC3-II occurred in $\beta 23$ mCherry cells (Fig 5A and B). Accordingly, the ratio of LC3-II levels with and without chloroquine was significantly reduced in $\beta 23-$ mCherry cells (Fig 5C), indicative of a partial block in the autophagylysosomal pathway.

Second, we assessed autophagic flux in primary neurons with the help of a tandem mCherry-GFP-LC3 reporter (Leeman et al, 2018). In the low pH conditions of functional lysosomes, the GFP fluorescence of the reporter is quenched and the organelles appear red. In contrast, less acidic organelles are marked with both GFP and mCherry and appear yellow (Fig 5D). For these experiments, we used myc-tagged $\beta 4$ protein not fused to mCherry (from here on myc- $\beta 4$ ). A rationally designed $\alpha$-helical protein with similar amino acid composition (myc- $\alpha$-S824) (Wei et al, 2003; Olzscha et al, 2011) served as a control. Expression of myc- $\beta 4$, but not myc- $\alpha-S 824$, resulted in aggregation and caused toxicity in neurons (Fig S5B and C). When each of these proteins was co-transduced into primary neurons together with the mCherry-GFP-LC3 reporter, the total number of fluorescent puncta was not different between myc- $\beta 4$ and myc- $\alpha$-S824 neurons (Fig 5E and F). However, in myc- $\beta 4$ cells, the number of yellow (non-acidic) puncta was increased, whereas the number of red-only (acidic) puncta was decreased (Fig 5G). These results argue against an overall increase in autophagy induction in the presence of the aggregating protein and confirm a defect in lysosomal degradation.

To further test whether autophagy induction was altered, we monitored the levels of the early autophagy markers Beclin 1 and ATG5 (Yamamoto \& Yue, 2014) in HeLa cells transfected with $\beta 23-$ mCherry. These markers were not significantly different in $\beta 23-$ mCherry and mCherry control cells (Fig $5 \mathrm{H}-\mathrm{I}$ ), suggesting that autophagosome formation was not affected by $\beta$ proteins. Consistently, early autophagosomes were rarely observed by cryo-ET in either control or $\beta$ protein-expressing neurons (Fig S4E, numbers of observations are provided in Table S2). In contrast, real-time PCR revealed that $\beta$ protein expression induced an up-regulation of transcripts of numerous lysosomal proteins (Fig 5J), a characteristic signature of aberrant lysosomal storage (Sardiello et al, 2009; Settembre et al, 2011). Taken together, our data suggest that $\beta$ protein aggregates do not affect early stages of autophagy, but impair lysosomal function.

\section{Interactome of $\beta$ proteins in neurons}

To search for the molecular causes of the observed lysosomal alterations, we characterized the interactome of $\beta$ proteins in neurons using quantitative label-free mass spectrometry (MS). In these experiments, we also used another mCherry-fused artificial amyloid- like protein called $\beta 17$. The aggregation propensity of the proteins increases from $\beta 4$ to $\beta 17$ to $\beta 23$ (West et al, 1999; Olzscha et al, 2011). Primary cortical neurons lentivirally transduced with $\beta$ proteins or mCherry were harvested at DIV $10+4$, a time point when $\beta$ proteins are still largely soluble and do not cause massive cell death (Fig S1). Immunoprecipitation against mCherry was then performed to isolate interactors, and the total proteome was also analyzed.

Using highly stringent criteria, we identified $30 \beta 4$-mCherry interactors, $54 \beta 17$-mCherry interactors and $59 \beta 23$-mCherry interactors, with an extensive overlap between the three $\beta$ proteins (Fig 6A-E and Table S3). In addition to confirming interactions found previously in non-neuronal cells (Olzscha et al, 2011), our approach uncovered a number of neuron-specific interactors, including several proteins linked to neurodegenerative disorders, such as Aimp1 (Armstrong et al, 2014), Mark4 (Rovelet-Lecrux et al, 2015), and Ppp2r5d (Louis et al, 2011) (Table S3). The most highly enriched protein in the interactome of all three $\beta$ proteins was AP-3 $\mu 1$, the medium subunit of the heterotetrameric AP-3 adaptor complex (Fig 6B-E). The AP-3 complex is involved in intracellular trafficking of transmembrane proteins, including protein transport to lysosomes (Newell-Litwa et al, 2007), and the medium subunit is responsible for cargo recognition (Ohno et al, 1998). Other prominent common interactors were Ccdc88a and Crmp1, two proteins involved in neuronal development and synaptic plasticity (Enomoto et al, 2009; Yamashita \& Goshima, 2012; Nakai et al, 2014). Of note, Ccdc88a plays a role in intracellular trafficking, among other functions (Le-Niculescu et al, 2005). Crmp1 is also found within mutant Huntingtin inclusions, and suppresses neurotoxicity in Huntington's disease models (Stroedicke et al, 2015).

Annotation enrichment analysis of the interactors revealed their involvement in key signaling pathways, such as "protein serine/ threonine kinase activity," "GTPase regulator activity," and "transport" (Fig S6A-C). Another enriched category was "microtubule," consistent with the impaired morphology of $\beta$ protein-expressing neurons (Fig $1 \mathrm{E}$ and F). In addition to these general cellular pathways, we found neuron-specific categories, such as "synapse," "postsynaptic cell membrane," and "neuron projection" (Fig S6A-C). In line with previous proteomic investigations of other aggregates (Olzscha et al, 2011; Kim et al, 2016; Woerner et al, 2016; Hosp et al, 2017), we observed a gradual increase in low-complexity regions in $\beta$ protein interactomes that paralleled their aggregation propensity (Fig S6D).

Analysis of the total proteome of transduced neurons (which includes the proteins interacting with the aggregates) did not reveal significant changes in the levels of any of the $\beta$ protein interactors (Fig S7A-D and Tables S3 and S4). This indicates that their presence in the interactome was not merely a result of their increased amounts in the cells, nor was their sequestration markedly compensated by increased expression. The unaltered total levels of the interactors, together with their enrichment in the interactome, suggest that the biologically active cellular pool of these proteins might be reduced, potentially leading to functional impairments.

\section{AP- $3 \mu 1$ is sequestered by $\beta$ protein aggregates, compromising the integrity of the AP-3 complex}

For further studies, we focused on AP- $3 \mu 1$ as the most highly enriched $\beta$ protein interactor. This protein made up $26 \%$ of the $\beta 4$ mCherry-interacting complexes, $17 \%$ for $\beta 17$-mCherry, and $10 \%$ for 
A

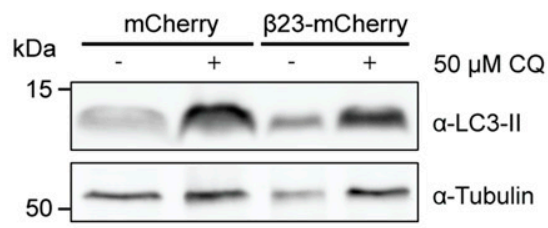

D

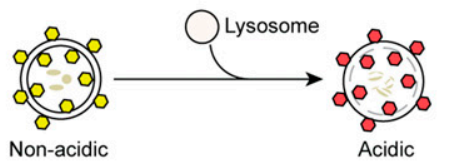

B

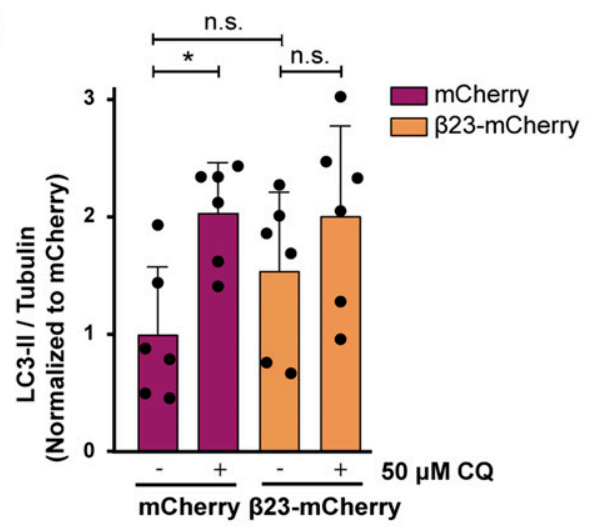

C

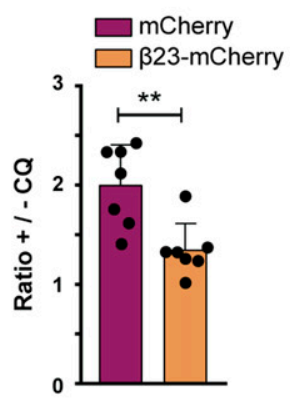

E

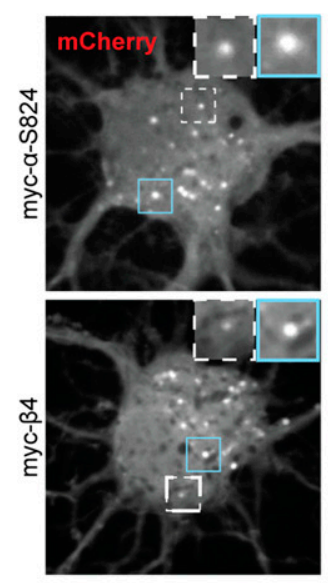

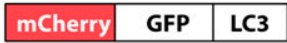

$\mathbf{F}$
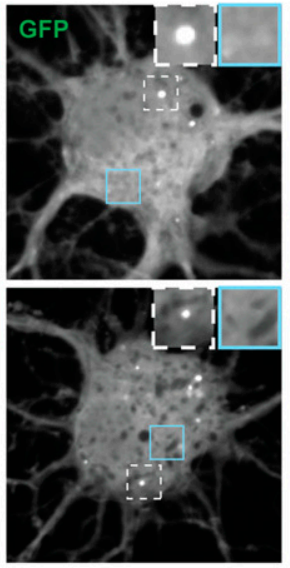
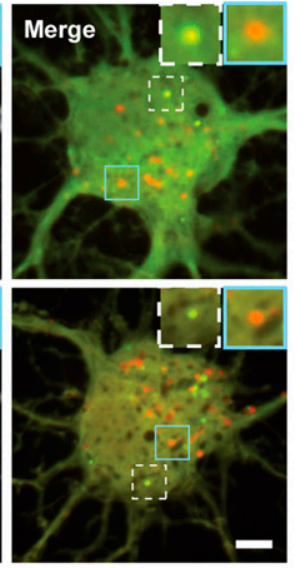

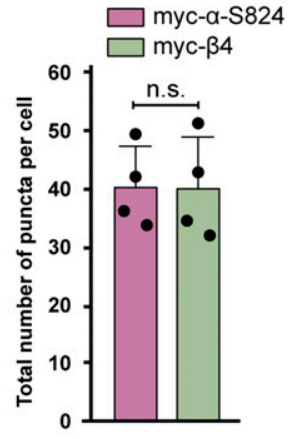

J

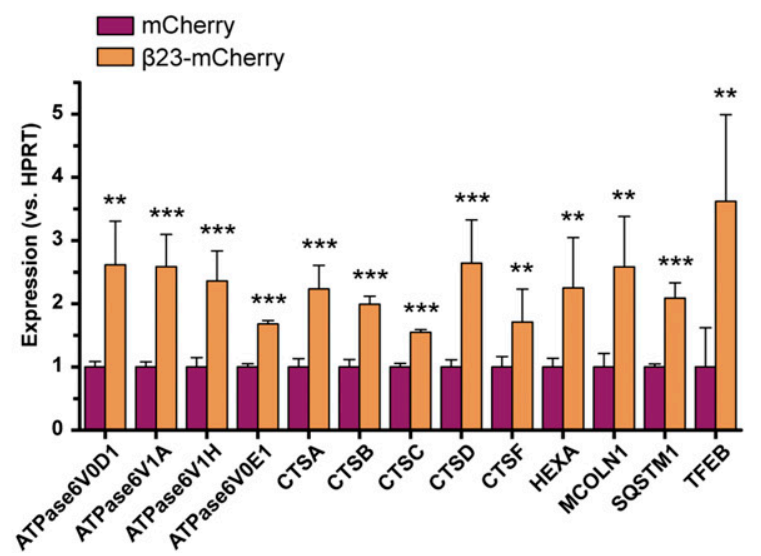

Figure 5. $\quad \beta$ proteins impair autophagy.

(A) Western blot for LC3B-II in HeLa cell lysates under control conditions and upon treatment with $50 \mu \mathrm{M}$ chloroquine. Tubulin was used as a loading control.

(B) Quantification of LC3B-II levels. All conditions were normalized to mCherry ( $n=6$ independent experiments; one-way ANOVA with Tukey's multiple-comparisons test). (C) Quantification of the ratio of LC3B-II levels in cells treated or not treated with chloroquine. Same data were analyzed as shown in (B) $(n=6$ independent experiments; two-tailed $t$ test with Welch's correction). (D) mCherry-GFP-LC3 reporter appears yellow in non-acidic and red in acidic organelles due to quenching of GFP fluorescence at low pH. (E) Single plane images of the reporter signal in DIV 10+3 neuronal cultures transfected with myc- $\alpha$-S824 (top) and myc- $\beta 4$ (bottom). Examples of non-acidic and 
B23-mCherry (Fig 6F-H), whereas its amount in the total proteome was not significantly changed (Fig S7B-D). In agreement with our MS data, both $\beta 4$-mCherry and $\beta 23$-mCherry co-immunoprecipitated with endogenous AP- $3 \mu 1$ in neurons (Fig S7E). As the interactome experiments were performed with the soluble fraction of neuronal lysates, we asked whether AP-3 $\mu 1$ is also present within $\beta$ protein aggregates. Using immunofluorescence, we found a high degree of colocalization between co-transfected AP-3 31 and $\beta$ protein aggregates (Fig $7 A$ and $B$ ). Cell fractionation experiments further revealed a significant accumulation of $A P-3 \mu 1$ in the pellet fraction of $\beta$ protein neurons (Fig $7 C-E$ ). These data show that $A P-3 \mu 1$ not only interacts with soluble $\beta$ proteins, but is sequestered by $\beta$ protein aggregates.

To test whether AP-3 31 is also sequestered by natural amyloids, we analyzed its colocalization with aggregates formed by the Tau repeat domain (TauRD, residues 244-372 with the point mutations P301L/ V337M, fused to EYFP), which mediates the assembly of tau fibrils (Crowther et al, 1992). Neurons transduced with TauRD-EYFP were treated with recombinant TauRD seeds to induce aggregation (Fig 7F) (Yuste-Checa et al, 2021). We observed significantly higher colocalization between TauRD-EYFP and endogenous AP-3 $\mu 1$ in neurons treated with seeds compared with non-seeded control cultures (Fig 7F and $\mathrm{G}$ ). In addition, AP-3 $\mu 1$ significantly accumulated in the pellet fraction of the seeded cultures (Fig $7 \mathrm{H}-\mathrm{J}$ ). Taken together, these data suggest that AP-3 $\mu 1$ can be substantially sequestered by different types of aggregates. As AP- $3 \mu 1$ is not highly abundant in neurons (Fig $\mathrm{S} 7 \mathrm{~F}$ ), its sequestration might result in a partial loss of function.

Defects in single subunits of the AP-3 complex have been previously shown to result in destabilization of the entire complex and premature degradation of its other subunits (Kantheti et al, 1998). We therefore quantified the levels of two other AP-3 complex subunits in $\beta$ protein neurons: AP-381, one of the large subunits, and AP-301, the smll subunit. Although these two subunits did not directly engage with $\beta$ proteins (Table S3), their levels significantly decreased (Fig 8 A and B) in $\beta$ protein cells (Fig S1A-D). These results suggest that the partial loss of the medium subunit leads to lower amounts of other AP-3 subunits and likely to a reduction in the levels of intact AP-3 complex in the cell. AP-3 complex deficiency is known to cause defects in biogenesis and function of lysosome-related organelles in mice and in humans, for example, in the rare genetic disorder Hermansky-Pudlak syndrome (Dell'Angelica \& Bonifacino, 2019). Thus, we hypothesized that AP-3 loss of function may play a role in the lysosomal defects and neurotoxicity caused by $\beta$ proteins.

\section{AP-3 function is impaired by $\beta$ proteins, leading to lysosomal defects}

To assess the function of the AP-3 complex in the presence of $\beta$ proteins, we determined the localization of the lysosomal protein Lamp1, a known cargo of AP-3. Lamp1 is at least partially trafficked via the plasma membrane, and then internalized and transported from the endosomal compartment to the lysosomes in an AP-3dependent manner (Peden et al, 2004). In conditions of AP-3 deficiency, Lamp1 is recycled from the endosomes back to the plasma membrane, leading to its accumulation at the cell surface (Dell'Angelica et al, 1999; Peden et al, 2002). Immunostaining for surface and total Lamp1 demonstrated significant mislocalization of the protein to the plasma membrane in both $\beta 4$-mCherry and $\beta 23$-mCherry neurons (Fig $8 C$ and D), suggesting that AP-3dependent transport of lysosomal proteins is impaired. Total Lamp1 levels were not changed in the proteome of $\beta$ protein-expressing neurons (Table S4 and Fig S7G).

Mice with a homozygous null mutation in AP-3 $\delta 1$ (mocha mice) exhibit defects in lysosome-related organelles such as melanosomes and platelet dense granules and show altered secretion of lysosomal enzymes in the kidney, suggesting that AP-3 loss-offunction causes impairments in lysosomes (Swank et al, 1991). We sought to confirm this in a mocha fibroblast cell line, and used functionally rescued mocha cells stably expressing the AP-381 subunit as control (Kent et al, 2012). In agreement with previous reports (Kantheti et al, 1998), the levels of AP-3 $\mu 1$ were severely reduced in mocha cells (Fig S8A-C), consistent with the instability of the whole complex in the absence of one subunit. When mocha cells were loaded with LysoTracker Red, we observed reduced numbers of lysosomes per cell (Fig $8 \mathrm{E}$ and F), in line with our findings in LysoTracker-labeled $\beta$ protein neurons (Fig 4C). These results confirm that impairment of the AP-3 complex leads to lysosomal defects.

To test whether re-supplying AP-3 31 would be sufficient to ameliorate $\beta$ protein toxicity, we quantified cell death in neuronal cultures co-transfected with $\beta$ proteins and AP-3 31 or EGFP as a control. Cleaved caspase-3 staining demonstrated that coexpression of AP-3 $\mu 1$ significantly reduced cell death in both $\beta 4$ $m$ Cherry and $\beta 23$-mCherry cells (Fig S8D and E). Therefore, impaired integrity and function of the AP-3 adaptor complex contributes to $\beta$ protein toxicity. Altogether, our data strongly suggest that lysosomal defects mediate, at least in part, the toxicity of $\beta$ protein aggregates in neurons.

\section{Discussion}

Here we used rationally designed aggregating proteins to understand the role of the aggregates' gain-of-function toxicity in neurons. It should be kept in mind that $\beta$ proteins differ from natural amyloids in several aspects. The solvent-exposed and buried face of the rationally designed proteins consist entirely of polar and non-polar amino acids, respectively, whereas natural amyloids present a more mixed structure. In addition, natural amyloid fibrils are wider and more resistant to disassembly than those made up of $\beta$ proteins

acidic organelles are indicated with white and blue boxes, respectively, and shown at higher magnification in the insets. (F) Quantification of the total number of reporter puncta per cell ( $n=4$ independent experiments; 15-45 cells/condition/experiment; two-tailed t test with Welch correction). (G) Quantification of the fraction of non-acidic (yellow) and acidic (red only) puncta. Same cells were analyzed as in (F) (two-way ANOVA with Sidak's post hoc test). (H) Western blots for early autophagy markers in lysates of HeLa cells transfected with mCherry or $\beta 23$-mCherry. HPRT was used as a loading control. (I) Western blot quantification ( $\mathrm{n}=5$ independent experiments; two-tailed $t$ test). (J) Transcript levels of lysosomal genes in mCherry or $\beta 23$-mCherry HeLa cells determined with RT-PCR ( $\mathrm{n}=6$ experiments; two-tailed $t$ test). Scale bar in (E), $5 \mu \mathrm{m}$. Data information: Data are presented as mean \pm SD. ${ }^{*} P<0.05 ;{ }^{* *} P<0.01$; ${ }^{* \star} P<0.001$; n.S., not significant. 
A

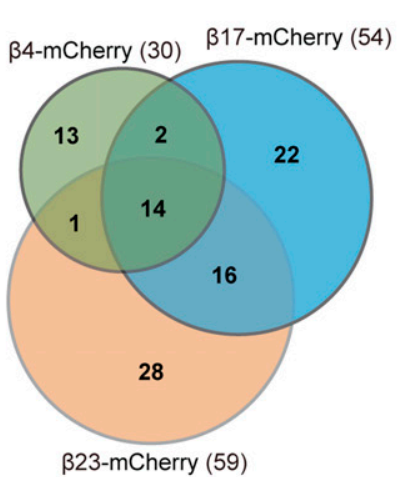

E

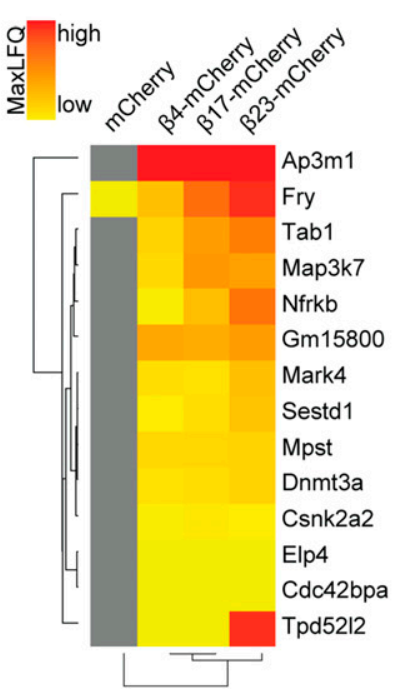

B

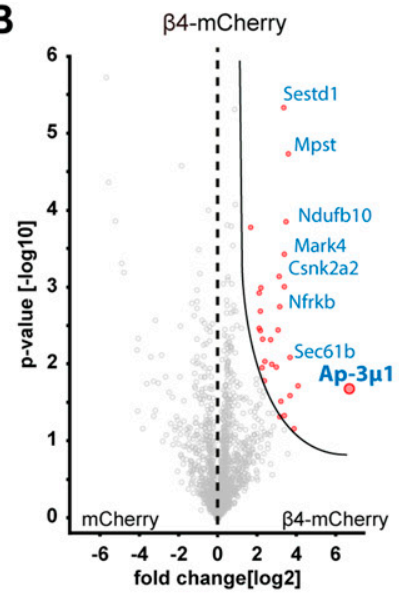

$\mathbf{F}$

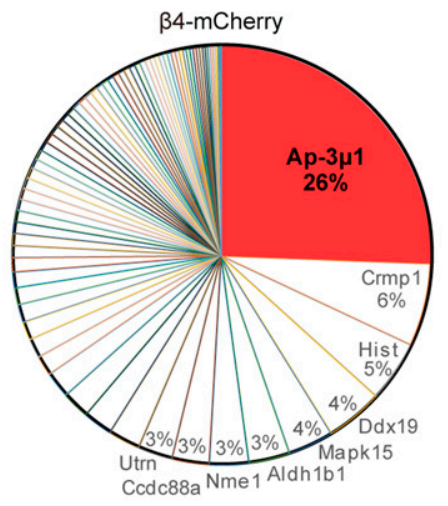

C

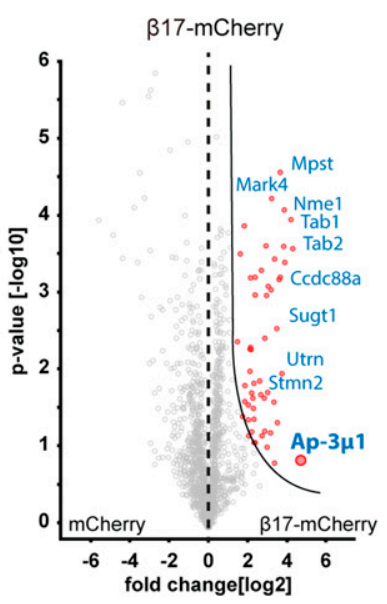

G
D

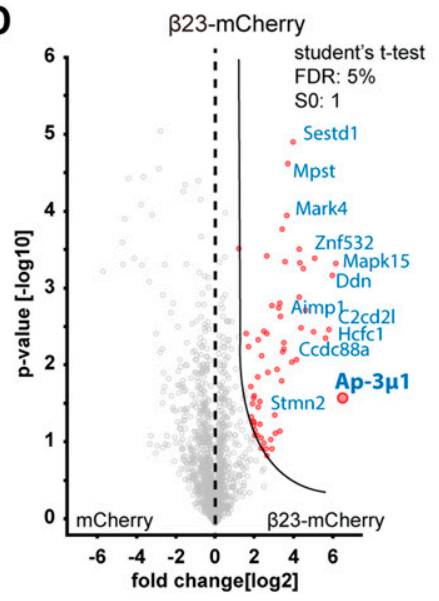

H
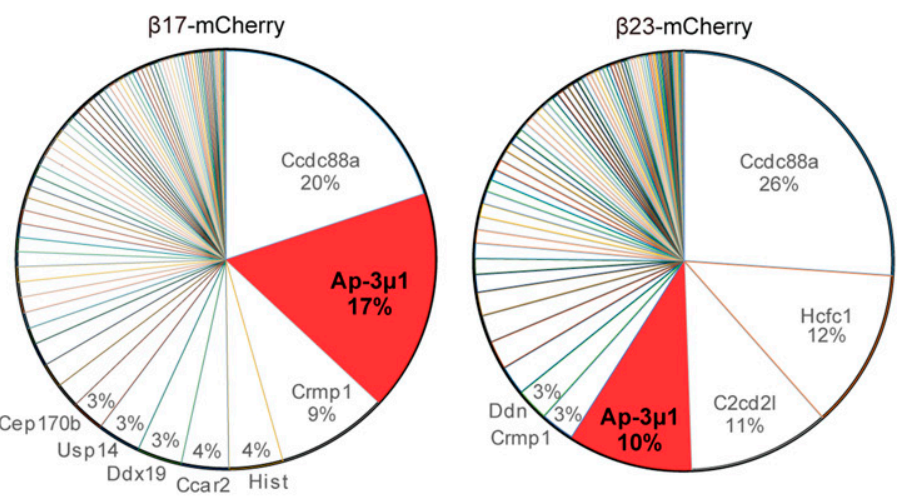

Figure 6. $\beta$ protein interactome in primary neurons.

(A) Venn diagram depicting numbers and overlap of interactors for the three $\beta$ proteins investigated. (B, C, D) Volcano plots depicting proteins significantly enriched in $\beta$ protein immunoprecipitates. Red dots denote proteins that pass $5 \%$ permutation-based false discovery rate (curved line on the right; proteins significantly associated with mCherry are not highlighted for the interactomes). (E) Heat map of common interactors of all three $\beta$ proteins. (F, $\mathbf{G}, \mathbf{H})$ Pie charts showing the quantitative composition of $\beta$ protein-interacting complexes.

(West et al, 1999; Olzscha et al, 2011; Fitzpatrick et al, 2017; Falcon et al, 2018; Zhang et al, 2020). Despite these limitations, $\beta$ proteins have proven very useful in unraveling general mechanisms of aggregate toxicity that apply to natural disease-related proteins (Olzscha et al, 2011; Woerner et al, 2016; Vincenz-Donnelly et al, 2018; Frottin et al, 2019). Apart from fibrillar aggregates, soluble oligomers may also play a role in the effects observed here, as a large fraction of the $\beta$ proteins remained soluble at the time point of the analyses (Fig S1).

Our integrated structural, functional, and molecular approach demonstrates that gain-of-function toxicity of aggregating proteins can be sufficient to cause lysosomal defects and neurotoxicity. These findings address a long-standing question regarding the role of aggregates as causative agents versus incidental by-products of disease progression (Haass \& Selkoe, 2007; Arrasate \& Finkbeiner, 2012) and conclusively show that protein aggregation per se has a deleterious impact on neurons. The toxicity mechanisms triggered by aggregating proteins are multifactorial and involve various cellular processes (Olzscha et al, 2011; Kim et al, 2016). Although our results are in agreement with this view, they point to lysosomal degradation as a pathway that is particularly vulnerable in primary neurons.

The lysosomal abnormalities that we observed in $\beta$ protein neurons are reminiscent of those reported in common neurodegenerative diseases such as Alzheimer's and Parkinson's (Suzuki \& Terry, 1967; Nixon et al, 2005; Dehay et al, 2012; Usenovic et al, 2012; Gowrishankar et al, 2015). One possible cause of lysosomal defects in protein misfolding disorders is that protein aggregates are targeted by the autophagy-lysosomal pathway (Filimonenko et al, 2010; Jo et al, 2014; Menzies et al, 2015; Hoffmann et al, 2019), but fail to be degraded by lysosomes, accumulating in these organelles and impairing their function (Lamark \& Johansen, 2012). In the case of $\beta$ proteins, this scenario seems unlikely because no aggregates were found within lysosomes by cryo-ET or light microscopy. 
A
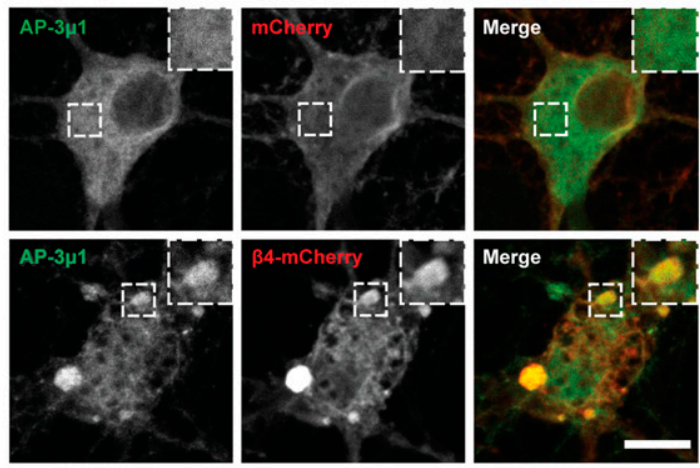

C

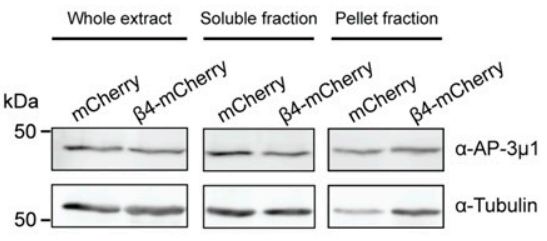

D

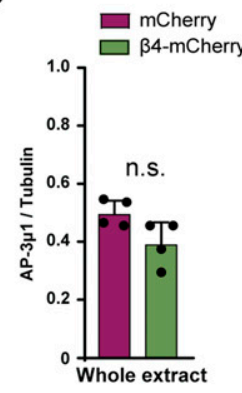

B

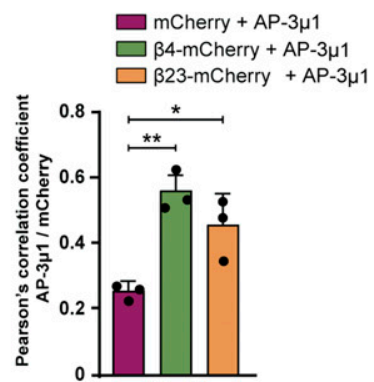

E

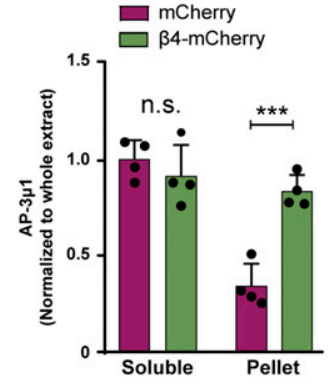

G

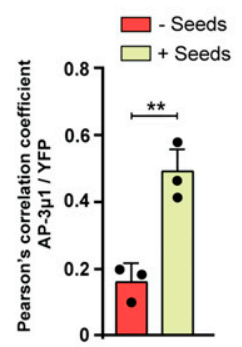

$\mathbf{J}$

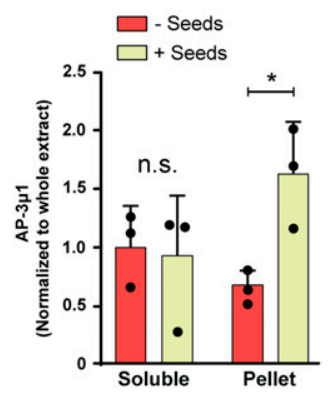

Figure 7. AP- $3 \mu 1$ is sequestered by aggregates, leading to defects of AP-3 complex.

(A) Single confocal plane images of DIV 10+2 cortical neurons co-transfected with Flag-AP-3 $\mu 1$ and either mCherry (top), or $\beta 4$-mCherry (bottom). Anti-Flag staining was

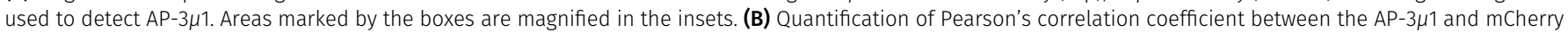
signal ( $n=3$ independent experiments, 20-30 cells/condition/experiment; one-way ANOVA with Tukey's post hoc test). (C) Western blots for AP-3 $\mu 1$ in whole lysates (left), Triton X-soluble fraction (middle), and pellet fraction (right) of DIV 10+6 primary neurons transduced with mCherry or $\beta 4$-mCherry. Tubulin was used as a loading

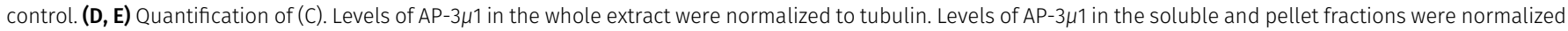


We propose that impaired trafficking of lysosomal proteins due to an insufficient cellular pool of intact AP-3 complex contributes to the lysosomal defects caused by $\beta$ protein aggregates. In agreement with previous studies investigating mutations in other AP-3 subunits (Peden et al, 2002), we show that reduced levels of AP-3 31 compromise the stability of the whole complex. In turn, AP-3 defects lead to missorting of lysosomal proteins and impair lysosomal function. AP-3 has been implicated in protein trafficking at different subcellular locations, such as direct transport from the Golgi apparatus or internalization from the plasma membrane via the endosomal pathway (Dell'Angelica et al, 1999; Peden et al, 2004; Li et al, 2016). In neurons, the AP-3 complex is also involved in the polarized sorting of proteins to the axonal compartment ( $\mathrm{Li}$ et al, 2016). Moreover, a number of other proteins related to intracellular transport and to other functions interact with $\beta$ proteins. Thus, the exact trafficking step(s) impaired by AP-3 deficiency in aggregatebearing neurons remain to be elucidated. It is also possible that impairment of cellular processes beyond lysosomal trafficking contributes to the deleterious effects of $\beta$ proteins.

Importantly, we show that AP-3 $\mu 1$ also accumulates in Tau aggregates. Moreover, previous proteomic studies demonstrated interactions of other AP-3 subunits with disease-related aggregating proteins. Thus, $A P-3 \beta 2$ was found to be an interactor of soluble Huntingtin (Shirasaki et $\mathrm{al}, 2012$ ), and together with AP-381 it was also identified as a component of insoluble mutant Huntingtin inclusions in the mouse brain (Hosp et al, 2017). AP-3 32 was among the most significant interactors of phosphorylated tau in human Alzheimer's disease brains (Drummond et al, 2020). Sequestration of other lysosomal proteins by aggregates and impaired trafficking of lysosomal enzymes was also described in synucleinopathies and in spinal and bulbar muscular atrophy (Chu et al, 2009; Dehay et al, 2012; Decressac et al, 2013; Cortes et al, 2014; Mazzulli et al, 2016). Therefore, compromised intracellular transport of lysosomal components may be an important factor in the pathogenesis of multiple neurodegenerative diseases.

\section{Materials and Methods}

\section{Plasmids}

For transfection, myc- $\beta 4$ and myc- $\beta 23$ (kind gift from Mark S Hipp and $F$ Ulrich Hartl) were cloned into pmCherry-N1 (Clontech) between KpnI and Agel restriction sites. pmCherry-N1 was used as control. The mouse AP-3 $\mu 1$ expression plasmid was purchased from OriGene (Ref. MR206629) and consists of AP-3 $\mu 1$-myc-DDK in pCMV6-ENTRY. For interactome analysis, myc-mCherry, myc- $\beta 4-m C h e r r y, ~ m y c-\beta 17-$ mCherry, and myc- $\beta 23$-mCherry were cloned into pENTR1A-164 between restriction sites Notl and EcoRI. For $\beta$ protein characterization in lentivirally transduced neurons, myc-mcherry and myc$\beta 23-\mathrm{mCherry}$ were cloned between $\mathrm{BamHI}$ and Xhol restriction sites of the plasmid pFhSynW2, whereas myc- $\beta 4$-mCherry was cloned between BamHI and EcoRV. Plasmids for lentiviral expression included the Kozak sequence CCCACC at the $5^{\prime}$ terminus of the insert. For lentiviral TauRD-EYFP expression, pFhSynW2 TauRD (P301L/ V337M)-EYFP was constructed by PCR amplification of the TauRD (P301L/V337M)-EYFP sequence from the N1-TauRD (P301L/V337M)EYFP plasmid (gift from Marc Diamond). The PCR product was then digested and subcloned into the pFhSynW2 using Xhol and Nhel restriction sites (Yuste-Checa et al, 2021).

\section{Lentivirus production}

Hek293T cells for lentiviral packaging were purchased (Lenti-X 293T cell line; Takara Bio) and expanded to $70-85 \%$ confluency in DMEM Glutamax (+4.5 g/L D-Glucose, - Pyruvate) supplemented with $10 \%$ FBS (Sigma-Aldrich), 1\% G418 (Gibco), 1\% NEAA (Thermo Fisher Scientific), and 1\% Hepes (Biomol). Only low-passage cells were used. For lentiviral production, three $T 75 \mathrm{~cm}^{2}$ flasks (Falcon) containing 5.7 million cells each were seeded and henceforth cultured in medium without G418. On the following day, cells were transfected with the expression plasmid pFhSynW2, and the packaging plasmids psPAX2 and pVsVg (all three kindly provided by Dieter Edbauer) using TransIT-Lenti transfection reagent (Mirus Bio). The transfection mix was incubated for $20 \mathrm{~min}$ at RT and in the meanwhile, cell medium was exchanged. $1 \mathrm{ml}$ transfection mix was added to each flask and left overnight. The medium was exchanged on the next day. After 48-52 h, culture medium containing the viral particles was collected and centrifuged for $10 \mathrm{~min}$ at 1,200g. Then, the supernatant was filtered through $0.45-\mu \mathrm{m}$-pore size filters using 50- $\mathrm{ml}$ syringes, transferred to Ultra-clear centrifuge tubes (Beckman Coulter), and centrifuged at 100,000 $\mathrm{g}$ for $2 \mathrm{~h}$ in the Avanti JXN30 centrifuge, rotor JS-24.38 (Beckman Coulter). Supernatant was discarded and the lentivirus pellet resuspended in TBS- 5 buffer ( 50 $\mathrm{mM}$ Tris- $\mathrm{HCl}, \mathrm{pH} 7.8,130 \mathrm{mM} \mathrm{NaCl}, 10 \mathrm{mM} \mathrm{KCl}$, and $5 \mathrm{mM} \mathrm{MgCl} 2$ ). After aliquoting, virus was stored at $-80^{\circ} \mathrm{C}$. For interactome analyses, lentivirus was produced using the pLV-Syn vector (derived from pLenti7.3-V5-Dest) and the packaging vectors pCMVdelta8.91 and pMD2_G (kindly provided by Alexandra Lepier).

\section{Preparation of EM grids}

R 2/1 Holey Carbon Au 200 mesh EM grids (Quantifoil) were coated with $20 \mathrm{~nm}$ of carbon in a MED 020 carbon coater (BAL-TEC) and made hydrophilic for $45 \mathrm{~s}$ in a PDC-3XG plasma cleaner (Harrick Scientific Products). For HeLa cell culture, the grids were

to its levels in the whole extract ( $n=4$ independent cultures; (D), two-tailed $t$ test with Welch's correction; (E), two-way ANOVA with Sidak's post hoc test). (F) Single confocal plane images of DIV 10+7 cortical neurons transduced with TauRD-EYFP, and treated with TauRD seeds (bottom) or PBS (top) on DIV 10+3. Areas marked by the boxes are magnified in the insets. (G) Quantification of Pearson's correlation coefficient between endogenous AP-3 11 and TauRD-EYFP ( $\mathrm{n}=3$ independent experiments, 20-30 cells/condition/experiment; two-tailed $t$ test with Welch's correction). (H) Western blots for AP-3 41 in whole lysates (left), Triton X-soluble fraction (middle) and pellet fraction (right) of DIV 10+7 cortical neurons transduced with TauRD-EYFP and treated or not treated with TauRD seeds. Tubulin was used as a loading control.

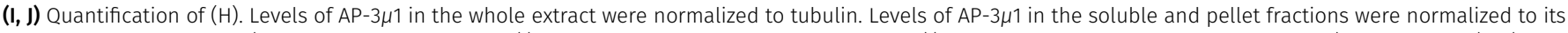
levels in the whole extract ( $n=3$ independent cultures; (I), two-tailed $t$ test with Welch's correction; (J), two-way ANOVA with Sidak's post hoc test). Scale bars in (A, F), 10 $\mu \mathrm{m}$. Data information: Data are presented as mean \pm SD. ${ }^{*} P<0.05,{ }^{* *} P<0.01,{ }^{* *} P<0.001$, n.s., not significant. 
A

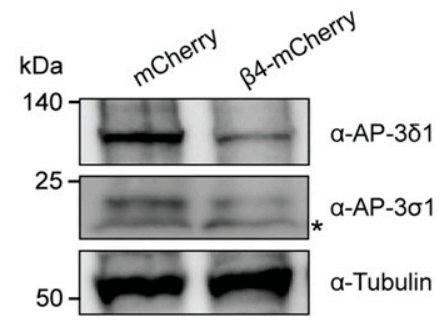

B

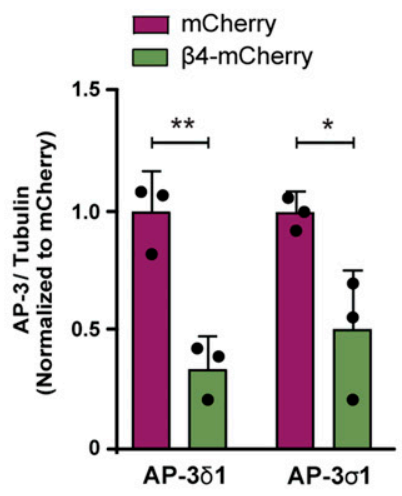

C
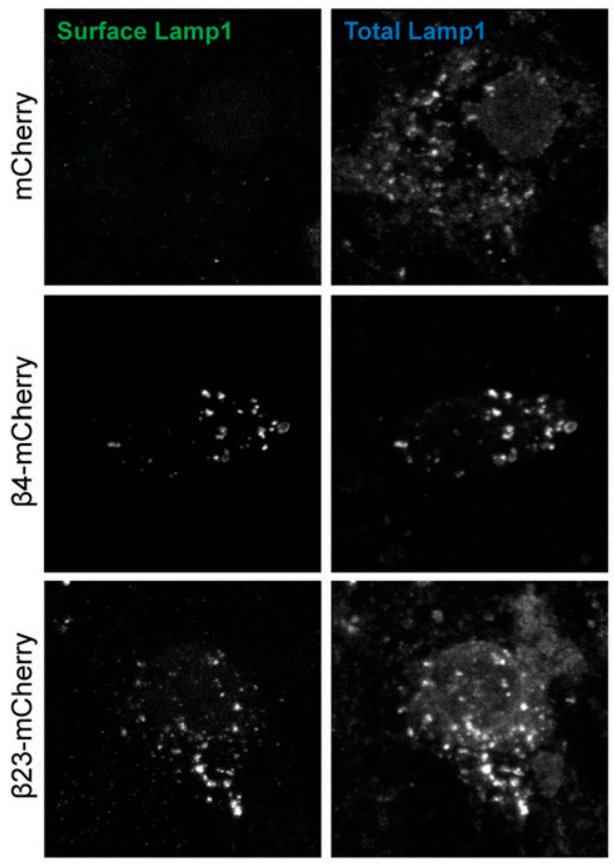

$\mathbf{E}$

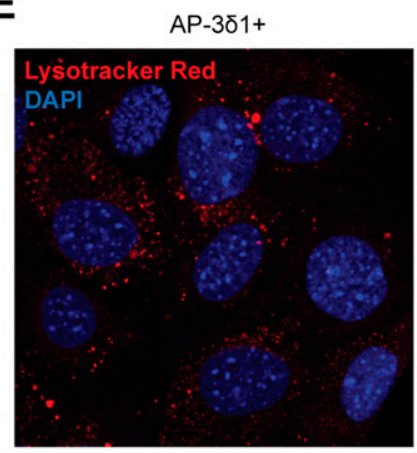

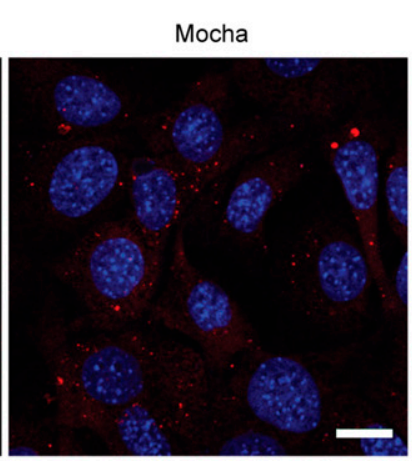
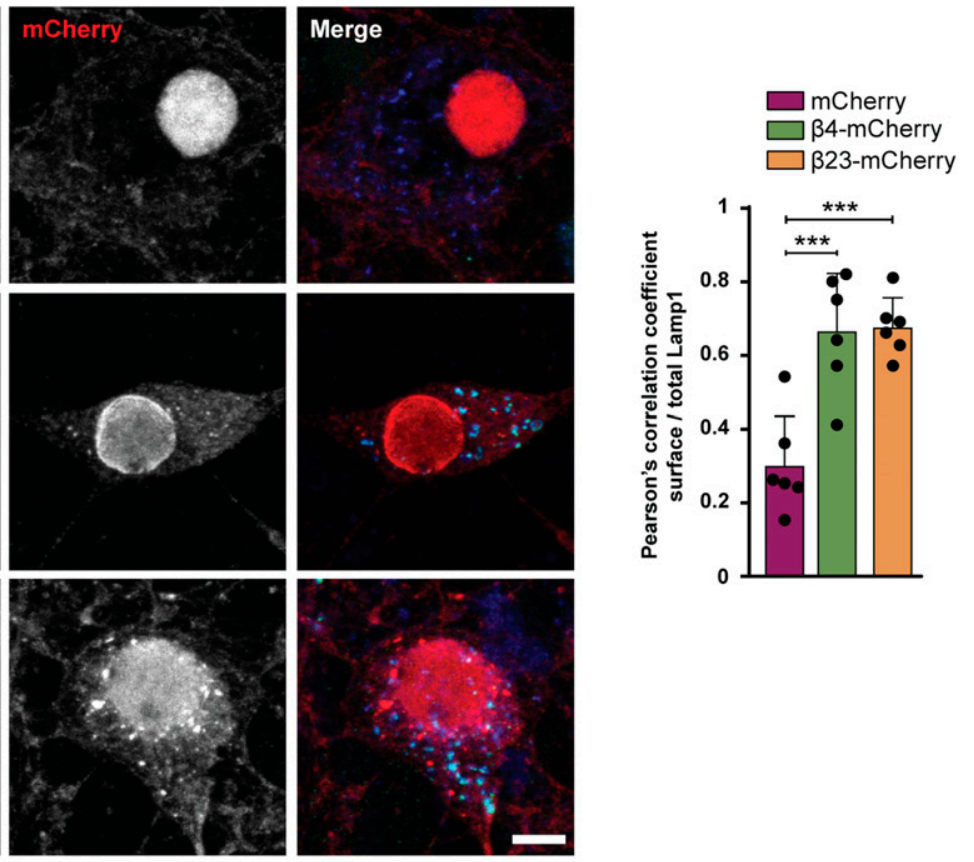

$\mathbf{F}$

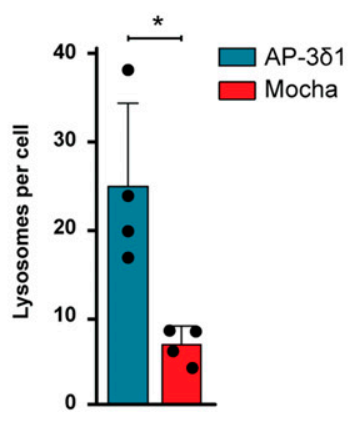

Figure 8. Dysfunction of the AP-3 complex causes missorting of Lamp1 and lysosomal defects.

(A) Western blots for AP-3 $\delta 1$ and AP-301 in whole lysates of DIV 10+6 primary neurons transduced with mCherry or $\beta 4$-mCherry. Asterisk marks an unspecific band. Tubulin was used as a loading control. (B) Quantification of $(A)(n=3$ independent cultures; two-tailed $t$ test with Welch's correction). (C) Maximum intensity projections of DIV 10+4 neurons transduced with mCherry (top), $\beta$ 4-mCherry (middle), or $\beta 23$-mCherry (bottom) and stained for surface (green) and total (blue) Lamp1. (D) Quantification of Pearson's correlation coefficient between surface and total Lamp1 signal ( $n=6$ independent experiments at DIV 10+4 and DIV 10+5, 25 cells/condition/experiment; one-way ANOVA with Dunnett's post hoc test). (E) Fluorescent images of control (left) and mocha cells (right) incubated with LysoTracker Red. Nuclei were labelled with DAPI (blue). (F) Quantification of lysosome numbers per cell ( $n=4$ independent experiments; at least 100 cells/condition/experiment; two-tailed $t$ test with Welch's correction). Scale bars; (C), $10 \mu \mathrm{m}$; (E), $20 \mu \mathrm{m}$. Data information: Data are presented as mean \pm SD. ${ }^{*} P<0.05,{ }^{* \star} P<0.01,{ }^{* \star *} P<0.001$. 
UV-sterilized in a Herasafe HR18 cell culture hood (Heraeus) for $30 \mathrm{~min}$. For neuronal cultures, the grids were sterilized in ethanol for $10 \mathrm{~min}$, washed several times in double-distilled water, and transferred to culture dishes containing water. Grids and dishes for neuronal cultures were coated with poly-D-lysine (Sigma-Aldrich; $1 \mathrm{mg} / \mathrm{ml}$ in borate buffer) for $24 \mathrm{~h}$ and washed three times with water. Subsequently, the grids were coated with laminin (Thermo Fisher Scientific; $5.0 \mu \mathrm{g} / \mathrm{ml}$ in PBS) for $24 \mathrm{~h}$, washed with PBS three times, and placed in Neurobasal medium supplemented with B27 containing $0.5 \mathrm{mM}$ Glutamine (all reagents from Thermo Fisher Scientific). During washes and medium exchange steps, grids were transferred into another dish containing the appropriate liquid to prevent them from drying.

\section{Primary neuron culture}

Primary neurons were prepared from E14.5-15.5 CD-1 or C57BL/6 wild-type embryos. All experiments involving mice were performed in accordance with the relevant guidelines and regulations of the Government of Upper Bavaria. Pregnant mice were euthanized by cervical dislocation, the uterus was removed from the abdominal cavity and placed into a $10-\mathrm{cm}$ sterile Petri dish on ice containing dissection medium, consisting of HBSS supplemented with $0.01 \mathrm{M}$ HEPES, $0.01 \mathrm{M} \mathrm{MgSO}_{4}$, and 1\% Penicillin/Streptomycin. Each embryo was isolated, heads were quickly cut, brains were removed from the skull, and immersed in ice-cold dissection medium. Subsequently, cortical hemispheres were dissected and meninges were removed under a stereo-microscope. For each sample, cortical or hippocampal tissue from typically six to seven embryos was transferred to a $15-\mathrm{ml}$ sterile tube and digested with $0.25 \%$ trypsin containing 1 mM 2,2',2",2'"'-(ethane-1,2-diyldinitrilo) tetraacetic acid (EDTA) and $15 \mu \mathrm{l} 0.1 \%$ DNAse I for $20 \mathrm{~min}$ at $37^{\circ} \mathrm{C}$. The enzymatic digestion was stopped by removing the supernatant and washing the tissue twice with Neurobasal medium (Invitrogen) containing 5\% FBS. The tissue was resuspended in $2 \mathrm{ml}$ medium and triturated to achieve a singlecell suspension. Cells were spun at 130-180g, the supernatant was removed, and the cell pellet was resuspended in Neurobasal medium with 2\% B27 (Invitrogen), 1\% L-glutamine (Invitrogen) and $1 \%$ penicillin/streptomycin (Invitrogen). For cryo-ET, neurons were plated on the coated grids within 24-well plates (60,000 per well). For MS analysis, cells were cultured on six-well plates (Thermo Fisher Scientific) (500,000 neurons per well) coated with $1 \mathrm{mg} / \mathrm{ml}$ poly-D-lysine (Sigma-Aldrich) and $1 \mu \mathrm{g} / \mathrm{ml}$ laminin (Thermo Fisher Scientific). For immunostaining, neurons were cultured on 13-mm coverslips, coated as above, in 24-well plates (Thermo Fisher Scientific). For MTT assay, neurons were cultured in coated 96-well plates. Transfection was performed using Calcium Phosphate according to the protocol from Jiang and Chen (2006) or using Lipofectamine 2000 (Thermo Fisher Scientific) according to the manufacturer's protocol. For lentiviral transduction, viruses were thawed and immediately added to freshly prepared neuronal culture medium. A fifth of the medium from cultured neurons was removed and the equivalent volume of virus-containing medium was added. Typically, $1 \mu \mathrm{l} / \mathrm{cm}^{2}$ of virus was added, but this amount was sometimes adjusted to match protein expression levels among different constructs. TauRD (residues 244-371, C291A/P301L/C322A/ V337M) seeds were kind gift of Patricia Yuste-Checa and were prepared as described (Yuste-Checa et al, 2021). Seeding was performed on DIV $10+3$ by adding $70 \mathrm{ng}$ of TauRD seeds mixed with fresh medium (1-10th of the medium in the well) to the neuronal cultures in 24-well plates.

\section{HeLa cell culture}

HeLa CCL-2 (ATCC) cells were grown in DMEM medium (Life Technologies) with 10\% FBS (Life Technologies), 0.5 mM L-glutamine (Life Technologies), 1\% MEM NEAA 100× (Life Technologies), and 1\% penicillin/streptomycin $\left(10,000 \mathrm{U} / \mathrm{ml}\right.$; Life Technologies) at $37^{\circ} \mathrm{C}$ and $5 \% \mathrm{CO}_{2}$. HeLa cells were transfected using FuGENE 6 transfection reagent (Promega) according to the manufacturer's instructions. For cryo-ET, $\sim 25,000$ cells were seeded in $35-\mathrm{mm}$ culture dishes (BD Falcon) containing four pre-treated EM grids $24 \mathrm{~h}$ before transfection. For Western blot experiments, cells were plated in $6 \mathrm{~cm}$ dishes $24 \mathrm{~h}$ before transfection (250,000 cells/ well). To inhibit autophagy, cells were treated with $50 \mu \mathrm{M}$ chloroquine in water (Sigma-Aldrich). HeLa cells were harvested 24-48 h after transfection.

\section{Mocha cell culture}

Mocha cells and control cells stably expressing AP-381 (AP-381+ cells) were kind gift of Andrew A Peden. Cells were cultured in DMEM supplemented with $10 \%$ FCS and $1 \%$ penicillin/streptomycin. For AP- $3 \delta 1+$ cells, $0.2 \mathrm{mg} / \mathrm{ml}$ hygromycin B was added to the medium. For lysosome counting, 100,000 cells were seeded onto glass coverslips. Cells were treated with $150 \mathrm{nM}$ LysoTracker Red (Thermo Fisher Scientific) for 30 min $1 \mathrm{~d}$ after seeding, washed with PBS and fixed with $4 \%$ PFA. Lysosomes were automatically quantified using a custom-made CellProfiler pipeline. For Western blot, 250,000 cells were seeded in six-well plates and harvested $1 \mathrm{~d}$ after seeding.

\section{Immunostaining}

Cells were fixed with 4\% PFA in PBS for $20 \mathrm{~min}$; remaining free groups of PFA were blocked with $50 \mathrm{mM}$ ammonium chloride in PBS for 10 min at RT. Cells were rinsed once with PBS and permeabilized with $0.25 \%$ Triton X-100 in PBS for 5 min. After permeabilization, cells were washed with PBS and blocked with $2 \%$ BSA (wt/vol) (Carl Roth) and $4 \%$ donkey serum (vol/vol) (Jackson Immunoresearch Laboratories) in PBS for 30 min at RT. Coverslips were transferred to a light-protected humid chamber and incubated in primary antibody diluted in blocking solution for $1 \mathrm{~h}$. The following primary antibodies were used: anti-mCherry (AB0040-200; OriGene, 1:500), antimyc 9E10 (13-2500; Thermo Fisher Scientific, 1:100), anti-cleaved caspase-3 (9661S; Cell Signaling Technology, 1:500), anti-Flag (TA50011-100; OriGene, 1:500), and anti-AP-3 $\mu 1$ (ab201227; Abcam, 1: 300). Cells were washed with PBS and incubated with secondary antibodies (Jackson Immunoresearch Laboratories) diluted 1:250 in blocking solution, with $0.5 \mu \mathrm{g} / \mathrm{ml}$ DAPI added to stain the nuclei. Coverslips were mounted on Menzer glass slides using Dako or Prolong Glass fluorescence mounting medium (Thermo Fisher Scientific). Confocal images were obtained at a spinning disc microscope (Zeiss) or SP8 confocal microscope (Leica). 
Colocalization analysis for AP-3 $\mu 1$ and $\beta$-mCherry proteins/ TauRD-EYFP was performed on single plane images. A regions of interest (ROI) was manually drawn around the soma of each cell in the mCherry/EYFP channel and the Image plug-in Coloc 2 was used to calculate the Pearson's correlation coefficient.

\section{Lamp1 staining}

Transduced cortical and hippocampal neurons were used. Stainings were performed at DIV 10+4 and 10+5 (three cultures for each time point) as described (Glynn \& McAllister, 2006). Briefly, live neurons cultured on coverslips were washed with ice-cold PBS and placed in a pre-cooled humid dark chamber that was kept on ice. Primary antibody (rat $\alpha$-Lamp1; Abcam, Reference ab25245) diluted 1:300 in blocking solution was added for $1 \mathrm{~h}$. After washing with icecold PBS, secondary antibody (donkey $\alpha$-rat 488) diluted 1:250 was added for $30 \mathrm{~min}$. Cells were washed with ice-cold PBS and fixed with ice-cold $4 \%$ PFA in PBS for $10 \mathrm{~min}$ at RT. Next steps were performed as described above in Immunostaining, using the same primary antibody, but changing the secondary to donkey a-rat 647 to differentiate between surface and total Lamp1.

Colocalization analysis was performed on maximum intensity projection images of transduced neurons. An ROI was manually drawn around the soma of each cell in the mCherry channel. A background subtraction of rolling ball radius of 50 pixels was performed in all images. The ImageJ plug-in Coloc 2 was used to calculate the Pearson's correlation coefficient between surface and total Lamp1.

\section{Neuronal viability measurements and Sholl analysis}

For transduced neurons, viability was determined with the MTT assay using Thiazolyl Blue Tetrazolium Bromide (MTT) reagent purchased from Sigma-Aldrich. Neurons were cultured in 96-well plates. First, cell medium was exchanged for $100 \mu \mathrm{l}$ of fresh medium. Then, $20 \mu \mathrm{l}$ of $5 \mathrm{mg} / \mathrm{ml}$ MTT in PBS was added and incubated for $2-4 \mathrm{~h}$ at $37^{\circ} \mathrm{C}, 5 \% \mathrm{CO}_{2}$. Subsequently, $100 \mu$ solubilizer solution ( $10 \%$ SDS, 45\% dimethylformamide in water, $\mathrm{pH} 4.5$ ) was added, and on the following day, absorbance was measured at $570 \mathrm{~nm}$. Each condition was measured in triplicates and absorbance values averaged for each experiment.

For transfected neurons, toxicity was quantified by an investigator blinded to the conditions based on immunostaining for cleaved caspase-3.

For Sholl analysis, mCherry channel was used to visualize neuronal morphology. Coverslips were immunostained against mCherry and imaged with a 40x objective. Maximum intensity projections were analyzed. First, cell morphologies were semiautomatically traced with the Simple Neurite Tracer plug-in of ImageJ in a blinded way. Then, complexity of the traced neurons was quantified with the Sholl analysis plug-in of ImageJ using a custommade macro for batch processing.

\section{Live cell light microscopy}

Samples were imaged using bright-field and epifluorescence widefield microscopy in a Corrsight microscope (FEI) using FEI MAPS 2.1 software. Low magnification overview images were acquired with a 5× air objective (Plan-ApoChromat, NA 0.16; Carl Zeiss). For high magnification image stacks, a $63 \times$ oil immersion objective (Plan Achromat, NA 1.4; Carl Zeiss) was used. Cells were kept on a $37^{\circ} \mathrm{C}$ heated stage in a homemade climate chamber infused with humidified air and $5 \% \mathrm{CO}_{2}$ gas. Cells were located at low magnification and z-stacks were acquired in $500 \mathrm{~nm}$ steps over the whole cell height at high magnification.

For the analysis of lysosome size and number, neuronal cultures expressing $\beta 23$-mCherry, $\beta 4$-mcherry, or mCherry were incubated with 75 nM LysoTracker Green DND-26 (Thermo Fisher Scientific) for 30 min according to the manufacturer's instructions. The mCherry signal was used to assess the cell perimeter and only lysosomes within that perimeter were measured. The mCherry signal of each cell was isolated by automatic thresholding using a homemade script written for Fiji software (Schindelin et al, 2012). The size of each lysosome was manually measured in its in-focus plane using Fiji software. The Pearson correlation coefficient was measured using JACOP plugin in Fiji software (Bolte \& Cordelieres, 2006).

For autophagy flux analysis with mCherry-GFP-LC3 reporter, primary cortical neurons were seeded in imaging plates with a glass-bottom (Nunc) and co-transfected at DIV 10 with the mCherryGFP-LC3 reporter (gift from Anne Brunet, plasmid \# 110060; Addgene) and either $\alpha$-S824 or myc- $\beta 4$ protein. Live imaging was performed at DIV 10+3 using a Spinning Disc Microscope SN 3834000224 (Zeiss) and the Visiview Software (Visitron Systems). Single imaging planes of each neuron were selected for quantification. The total number of puncta and the number of yellow puncta were manually quantified for each neuron. The number of red puncta was calculated by subtracting the number of yellow puncta from the total. All quantifications were performed in a blinded fashion to the analyzed condition.

\section{Sample vitrification}

Cells were vitrified using a homemade manual gravity-driven plunge freezer. Before plunge-freezing, cells were treated with $10 \%$ glycerol (Sigma-Aldrich) in medium as a cryoprotectant for 1-5 min. In addition, in some cases, cells were stained with 3\% Annexin $\checkmark$ and Alexa Fluor 488 conjugate (Life Technologies) 15 min before vitrification to identify dead cells. During plunge freezing, EM grids were blotted for $8 \mathrm{~s}$ with filter paper No. 1 (Whatman) from the back side and immediately frozen in liquid ethane/propane (37\%/63\%; Linde) kept at liquid nitrogen temperature. Grids were transferred to liquid nitrogen and excess ethane/propane was blotted with pre-cooled filter paper. Grids were stored in liquid nitrogen until further use.

\section{Cryo-light microscopy}

Frozen grids were fixed into FIB C-clip rings to increase mechanical stability. Samples were transferred to a CorrSight shuttle (FEI) and mounted on the Corrsight cryo-stage (FEI) maintained at liquid nitrogen temperature for cryo-light microscopy. Samples were imaged using wide-field or spinning-disk confocal, epifluorescence microscopy using FEI MAPS 2.1 software. Images were acquired with a 1,344 × 1,024 pixel camera (pixel size $6.4 \mu \mathrm{m}$, Hamamatsu Digital 
Camera C10600 ORCA-R2). Grids were imaged in wide-field mode at low magnification with a $5 \times$ air objective (Plan-ApoChromat, NA 0.16; Carl Zeiss) and in spinning-disk confocal mode at high magnification with a 40× air objective (EC Plan-Neofluar, NA 0.9; Carl Zeiss) for identification of cells and/or aggregates. Image acquisition and further SEM correlation was performed by three-point correlation using FEI MAPS 2.1 software.

\section{Cryo FIB SEM}

Grids imaged by light microscopy were mounted on a transfer shuttle designed for a cryo-loading system (Rigort et al, 2010) and loaded into a Quanta 3D FEG dual-beam FIB/SEM (FEI). Grids were sputtered with platinum (10 mA, $30 \mathrm{~s}$ ) in a PP3000T loading system (Quorum) to reduce charging effects during electron imaging. Grids were loaded into the FIB chamber and coated with organometallic platinum as a protective layer for ion beam milling. Grids were imaged with the scanning electron beam operated at $5 \mathrm{kV} / 12 \mathrm{pA}$ and ROI were identified via cryo-LM/SEM three-point correlation using MAPS 2.1 software. ROIs were thinned down at tilt angles of $18^{\circ}-20^{\circ}$ with the focused ion beam operated at $30 \mathrm{kV}$. The beam currents where set to $1 \mathrm{nA}$ at $\sim 1 \mu \mathrm{m}$ distance from the ROI, $500 \mathrm{pA}$ at $750 \mathrm{~nm}$, $300 \mathrm{pA}$ at $400 \mathrm{~nm}, 100 \mathrm{pA}$ at $250 \mathrm{~nm}, 50 \mathrm{pA}$ at $100 \mathrm{~nm}$, and $30 \mathrm{pA}$ at 75 $\mathrm{nm}$ for polishing. Grids were sputtered once more with platinum (10 $m A, 5 \mathrm{~s}$ ) after milling to increase conductivity of the lamellae for VPP imaging.

\section{Cryo-ET}

Cryo-TEM was performed on a Titan Krios cryo-TEM (FEI) operated at $300 \mathrm{kV}$, equipped with a FEG, post-column energy filter (Gatan) and Volta phase plate (Danev et al, 2014). Tomograms were acquired on a K2 Summit direct electron detector (Gatan) in dose fractionation mode (0.08 frames per second) using SerialEM (Mastronarde, 2005). Lamella overview images were acquired at 3,600× magnification (pixel size: $38.93 \AA$ ) and stitched using the automatic photo merge in Adobe Photoshop. For cryo-LM - cryo-TEM correlation, stitched lamella TEM overview images were imported into MAPS and aligned with cryo-LM data. Tilt series were recorded at $-0.5 \mu \mathrm{m}$ defocus for VPP imaging at 33,000× magnification (pixel size: $4.21 \AA$ ), with an angular increment of $2^{\circ}$ and typically ranged from $-50^{\circ}$ to $60^{\circ}$. The total dose was restricted to $\sim 120$ electrons $/ \AA^{2}$ per tomogram.

\section{Tomogram reconstruction and data processing}

K2 frames were aligned and combined using in-house software based on previous work (Li et al, 2013). Tilt series were aligned using patch tracking from the IMOD software package (Kremer et al, 1996) and reconstructed by weighted back projection. The platinum layer for VPP imaging and large pieces of surface ice contamination were computationally removed to increase signal-to-noise ratio (Fernandez et al, 2016). The resulting tilt series were realigned and reconstructed again. Tomograms were binned four times to a final pixel size of $16.84 \AA$ to increase contrast.

Tomogram segmentation was performed using Amira (FEI). Membranes and microtubules were automatically segmented using TomoSegMemTV (Martinez-Sanchez et al, 2014) and corrected using
Amira. $\beta$-protein fibrils were traced on denoised tomograms (nonlocal means filter) by removing membranes and macromolecules followed by density thresholding and subsequent skeletonization. For the identification of ribosome positions, template matching was applied using the pyTOM toolbox in MATLAB (Mathworks) as previously reported (Hrabe et al, 2012). A human $80 \mathrm{~S}$ ribosome structure (PDB: 4UGO) (Khatter et al, 2015) was filtered to $40 \AA$ and used as a template. Coordinates of ribosomes identified via template matching were imported into Amira and masked with the filtered molecular structure. The diameter of the $\beta$ protein fibrils was measured in tomograms from neurons using IMOD.

\section{Western blotting}

Cells were lysed in $50 \mathrm{mM}$ Tris- $\mathrm{HCl}$, pH 7.4, $150 \mathrm{mM} \mathrm{NaCl}, 2$ mM EDTA, and $1 \%$ Triton X-100 with protease and phosphatase inhibitor tablets (Roche). Lysates were centrifuged for $10 \mathrm{~min}$ at 4,000 (neurons) or $14,000 \mathrm{~g}$ (HeLa) and $4^{\circ} \mathrm{C}$ and supernatants were collected (soluble fraction). Pellets were used as insoluble fraction, whole extracts were used as total. Proteins were separated on $12 \%$ or 15\% SDS-PAGE gels and transferred onto polyvinylidene difluoride (PVDF) membranes using a Trans-Blot Turbo transfer system (Bio-Rad). Blocking was performed with 3\% BSA, 5\% dried milk (Roth) in TBS-T for $1 \mathrm{~h}$ at RT. Primary antibodies were diluted 1 : 1,000 in $3 \%$ BSA in TBS-T, $0.01 \%$ sodium azide and incubated for 1 or $2 \mathrm{~d}$ at $4^{\circ} \mathrm{C}$. Secondary antibodies were diluted 1:5,000 in 5\% dried milk in TBS-T and applied for $2 \mathrm{~h}$ at RT. Tubulin-Rhodamine (BioRad) was diluted 1:2,500 and added together with the secondary antibodies. Detection was performed using the Chemidoc MP imaging system (Bio-Rad). Primary antibodies used were antiLC3B (D11) (3868; Cell Signaling Technology), anti-p62 (ab56416; Abcam), anti-GFP (632381; Clontech), hFAB rhodamine anti-tubulin (12004166; Bio-Rad), anti-myc 9E10 (13-2500; Thermo Fisher Scientific), anti-Atg5 (D5F5U; Cell Signaling Technology), anti-beclin-1 (3495; Cell Signaling Technology), anti-HPRT (ab10479; Abcam), anti-AP-3 11 (ab201227; Abcam), anti-AP-381 (kind gift from Andrew A Peden), anti-AP-301 (TA319631; OriGene), and anti-tubulin (T9026; Sigma-Aldrich). For fluorescent Western blots, secondary antibodies were StarBright Blue 520 Goat Anti-Mouse, StarBright Blue 520 Goat Anti-Rabbit, StarBright Blue 700 Goat Anti-Mouse, and StarBright Blue 700 Goat Anti-Rabbit. For chemiluminescent Western blots, secondary antibodies were anti-rabbit HRP (NA934; Thermo Fisher Scientific) and anti-mouse HRP (NA931; Thermo Fisher Scientific). Band density quantification was performed with ImageJ and normalized to loading controls.

\section{Quantitative RT-PCR}

RNA isolation and purification was performed using a Crystal RNA mini Kit (Biolab) according to the manufacturer's instructions. RNA quantification and quality control were performed with a NanoDrop spectrophotometer (PeqLab). cDNA was synthesized using a HighCapacity cDNA Reverse Transcription Kit (Applied Biosystems) according to the manufacturer's instructions. cDNA was diluted 1:50, each $8-\mu \mathrm{l}$ reaction contained $4 \mu \mathrm{l}$ diluted CDNA, $0.2 \mu \mathrm{l}$ dilutions of each primer ( $25 \mu \mathrm{M}$ stock), and $3.6 \mu$ L Luna Universal Probe qPCR 
Master Mix (New England BioLabs). The primers were described previously (Fernandez-Mosquera et al, 2017).

\section{Immunoprecipitation}

For AP-3 41 immunoprecipitation, lysates of transduced cortical neurons cultured in six-well plates were incubated overnight with $2 \mu \mathrm{l}$ of rabbit $\alpha$-AP-3 $\mu 1$ antibody (Reference ab201227; Abcam) on a rotating wheel at $4^{\circ} \mathrm{C} .50 \mu \mathrm{l}$ of Protein G Sepharose 4 Fast Flow (Sigma-Aldrich) slurry were washed, resuspended in lysis buffer (50 $\mathrm{mM}$ Tris- $\mathrm{HCl}, \mathrm{pH} 7.4,150 \mathrm{mM} \mathrm{NaCl}, 2$ mM EDTA, and 1\% Triton X-100 with protease and phosphatase inhibitor tablets [Roche]), and added to the lysates. The mix was incubated for $2 \mathrm{~h}$ at RT on a rotating wheel. Further steps were performed as described by the manufacturer, but performing all washes with lysis buffer.

For interactome analysis, cortical neurons (500,000 cells/condition) were harvested in ice-cold lysis buffer (0.25\% NP40, 5\% glycerol, 50 mM Tris $\mathrm{HCl}$, and $150 \mathrm{mM} \mathrm{NaCl}$ ) containing protease inhibitor (Roche), DNAse ( $5 \mu \mathrm{l} /$ $\mathrm{ml})$ and RNAse $(0.5 \mu \mathrm{l} / \mathrm{ml})$. Thermo Fisher Scientific Pierce Protein $\mathrm{G}$ Agarose $(10 \mu \mathrm{l} / 100 \mu \mathrm{g}$ IgG) was used for purification and immunoprecipitation of IgG antibodies. Serum samples containing IgG were incubated with Protein $\mathrm{G}$ agarose in a buffer that facilitates binding $(20 \mathrm{mM}$ sodium phosphate) for $1 \mathrm{~h}$. Then, neuronal lysates were loaded onto IgG-protein $\mathrm{G}$ Agarose and incubated for $4 \mathrm{~h}$. Non-IgG and non-antigen components were discarded from the sample by washing with 0.1\% NP40, 5\% glycerol, $50 \mathrm{mM}$ Tris HCl, and $150 \mathrm{mM} \mathrm{NaCl}$. Enriched proteins were next isolated and processed in a step-wise manner. First, proteins were denatured, digested, and cysteines reduced for $1 \mathrm{~h}$ at $20^{\circ} \mathrm{C}$ by adding $8 \mathrm{M}$ urea, $40 \mathrm{mM}$ Hepes, $\mathrm{pH} 8.0,1 \mu \mathrm{g}$ LysC, and $10 \mathrm{mM}$ DTT. Next, urea concentration was lowered to $2 \mathrm{M}$ by adding $50 \mathrm{mM}$ ammonium bicarbonate in MilliQ water. Trypsin $(1 \mu \mathrm{g})$ was added to the protein-peptide mix and samples were subjected to $55 \mathrm{mM}$ chloroacetamide for $1 \mathrm{~h}$ to alkylate cysteine residues. Alkylation was quenched by adding $2 \mathrm{M}$ urea/50 mM thiourea and overnight digestion was carried out after addition of $1 \mu \mathrm{g}$ fresh trypsin. Interactome analysis was conducted in four independent biological replicates.

\section{Complete neuronal proteome precipitation}

Complete neuronal proteomes were extracted as described previously (Hornburg et al, 2014). In brief, cells were lysed in lysis buffer (4\% SDS and 10 mM Hepes, pH 8.0) and reduced with 10 mM DTT for 30 $\mathrm{min}$. The proteins were then subjected to $45 \mathrm{~min}$ of alkylation with 55 $\mathrm{mM}$ iodoacetamide. Acetone precipitation was performed to remove the SDS. Acetone $\left(-20^{\circ} \mathrm{C}\right)$ was added to $100 \mu \mathrm{g}$ of proteins to a final concentration of $80 \% \mathrm{vol} / \mathrm{vol}$, and proteins were precipitated overnight at $-20^{\circ} \mathrm{C}$. The supernatant was removed after $15 \mathrm{~min}$ of centrifugation $\left(4^{\circ} \mathrm{C}, 16,000 \mathrm{~g}\right)$ followed by washing with $80 \%$ acetone $\left(-20^{\circ} \mathrm{C}\right)$. Residual acetone was evaporated at $20^{\circ} \mathrm{C}$. The protein pellet was dissolved in $50 \mu$ of $6 \mathrm{M}$ urea/2 M thiourea and $10 \mathrm{mM}$ Hepes, $\mathrm{pH}$ 8.0. LysC $(1 \mu \mathrm{g})$, and digestion was carried out for $2 \mathrm{~h}$ at $20^{\circ} \mathrm{C}$. The samples were incubated with $1 \mu \mathrm{g}$ trypsin for overnight digestion and peptides were desalted on C18 solid phase extraction.

\section{Solid phase extraction}

Stage Tips were prepared with $3 \times \mathrm{x} 18$ material for rapid desalting and step elution of the peptide mixtures. Stage Tips were rinsed with $\mathrm{MeOH}$ and buffer $\mathrm{A}$ ( $0.5 \%$ acetic acid). Samples were added to the staging tips and washed with buffer A. Buffer B (80\% acetonitrile and $0.5 \%$ acetic acid) was used to elute the samples. Speedvac was used to remove the solvent from the samples. The samples were then resuspended in $10 \mu \mathrm{l}$ buffer $A^{*}(0.5 \% \mathrm{AcOH}, 0.1 \%$ TFA, and $2 \%$ ACN).

\section{LC-MS/MS}

Peptides were separated on EASY-nLC 1000 HPLC system (Thermo Fisher Scientific). Columns (75- $\mu \mathrm{m}$ inner diameter, $40-\mathrm{cm}$ length) were in-house packed with 1.9- $\mu \mathrm{m}$ C18 particles (Dr. Maisch $\mathrm{GmbH}$, Ammerbuch-Entringen, Germany). Peptides were loaded in buffer A (0.5\% formic acid) and separated with a gradient from $7 \%$ to $60 \%$ buffer B ( $80 \%$ acetonitrile, $0.5 \%$ formic acid) within 3 h 30 min at 200 $\mathrm{nl} / \mathrm{min}$. The column temperature was set to $60^{\circ} \mathrm{C}$. A quadrupole Orbitrap mass spectrometer (Q Exactive; Thermo Fisher Scientific) was directly coupled to the liquid chromatograph via a nanoelectrospray source. The $\mathrm{Q}$ Exactive was operated in a datadependent mode. The survey scan range was set to 300-1,650 $\mathrm{m} / \mathrm{z}$, with a resolution of 70,000 at $\mathrm{m} / \mathrm{z} 200$. Up to 15 most abundant isotope patterns with a charge of $\geq 2$ were subjected to higher energy collisional dissociation (Olsen et al, 2007) with a normalized collision energy of 25 , an isolation window of $2 \mathrm{Th}$, and a resolution of 17,500 at $\mathrm{m} / \mathrm{z} 200$. To limit repeated sequencing, dynamic exclusion of sequenced peptides was set to $30 \mathrm{~s}$. Thresholds for ion injection time and ion target value were set to $20 \mathrm{~ms}$ and $3 \times 10 \times 10^{6}$ for the survey scans and to $60 \mathrm{~ms}$ and $10 \times 10^{6}$ for the MS/MS scans. Data were acquired using Xcalibur software (Thermo Fisher Scientific).

\section{MS data analysis}

To process MS raw files, we used MaxQuant software (v. 1.5.7.10) (Cox \& Mann, 2008). Andromeda (Cox et al, 2011), which is integrated into MaxQuant, was used to search MS/MS spectra against the UniProtKB FASTA database. For the standard immunoprecipitation and pre-loaded serum, enzyme specificity was set to trypsin and LysC. For all the experiments, $\mathrm{N}$-terminal cleavage to proline and up to two miscleavages was allowed. Peptides with a minimum length of seven amino acids were considered for identification. Oxidation, acetylation, and deamidation were set as variable modifications (maximum number of modifications per peptide was 5). A false discovery rate (FDR) cut-off of $1 \%$ was applied at the peptide and protein levels. Initial precursor mass deviation of up to $4.5 \mathrm{ppm}$ and fragment mass deviation up to 20 ppm were allowed. Precursor ion mass accuracy was improved by time-dependent recalibration algorithms in MaxQuant. The cut-off score (delta score) for accepting individual MS/MS spectra was 17.

The proteome fasta file from Mus musculus (Taxon identifier: 10090) was used as a library for matches. Nonlinear retention time alignment (Cox \& Mann, 2008; Cox et al, 2011) of all measured samples was performed in MaxQuant. "Match between runs," which allows the transfer of peptide identifications in the absence of sequencing, was enabled with a maximum retention time window of $0.7 \mathrm{~min}$. Furthermore, we filtered our data by requiring a minimum peptide ratio count of 1 in MaxLFQ. Protein identification 
required at least one razor peptide (Cox \& Mann, 2008). Proteins that could not be discriminated on the basis of unique peptides were grouped into protein groups. Co-immunoprecipitated proteins were considered interactors if they were significantly enriched compared with the control samples applying a 5\% permutationbased FDR cut-off (see below).

For statistical and bioinformatic analysis, as well as for visualization, we used the open Perseus environment, which is part of MaxQuant. The numerical data were transformed to $\log _{2}(\mathrm{x})$. Proteins were filtered for common contaminants; proteins identified only by site modification and reverse proteins were excluded. Missing values in pairwise comparisons were imputed with a normal distribution ( width $=0.3 \times$ SD; down shift $=1.8 \times$ SD) in Perseus. Proteins were only considered if they were detected with at least three valid values among quadruplicates in at least one condition. For pairwise comparison of proteomes and determination of significant differences in protein abundances, $t$ test statistics were applied with a permutation-based FDR of $5 \%$ and S0 of 1 . The resulting significant outliers for each of the sample pairs were analyzed for gene ontology (GOCC) (Harris et al, 2004), biological ontology (GOBP), molecular function (GOMF), protein complexes (CORUM) (Ruepp et al, 2010), and protein families and domains (Pfam) (Finn et al, 2014) annotation enrichments. The data were displayed in a scatter plot for visual representation. For protein abundance ranking, summed peptide intensities from MaxQuant (median of at least three valid values within quadruplicates) were divided by the molecular weight to adjust for protein size bias and estimate the abundance rank of each protein within the proteome. $\log _{10}$ corrected intensities were plotted against the rank.

To calculate the content of disordered regions, we used R (rjson and seqinr libraries). First, amino acids that are predicted with lowcomplexity long region (IUPred-L) were mapped to sequences of proteins that are significant outliers in either of the $\beta$ protein interactomes as well as for the entire population of proteins identified in the interactomes. Next, the ratio of all amino acids and those predicted with low complexity was calculated. To determine the significance of differences between the individual populations, a two-sample Wilcoxon test was performed on the ratio distributions.

\section{Aggregate composition estimation}

To estimate the relative mass composition of the protein aggregates, the median of $\log _{2}$ MaxLFQ intensity (requiring at least two valid values) was calculated across quadruplicates for the $\beta$ protein samples and the mCherry controls, respectively. Missing values in the mCherry samples were imputed with a normal distribution on the $\log _{2}$ scale $($ width $=0.3 \times$ SD; down shift $=1.8 \times$ SD). Next, the non$\log$ (median) intensity of each protein in the $\beta$ protein samples was subtracted by the respective non-log intensity derived from the mCherry samples. This transformation corrects for the overall background signal in the immunoprecipitation. The resulting intensities roughly correspond to the relative abundance in the aggregate (=composition) and are plotted as fractions in pie charts. Note that we did not apply an FDR or P-value cut-off for this analysis. By subtracting protein intensity of the mCherry controls from those in the $\beta$ protein samples, small differences (which associate with larger $P$-values and FDRs) have a diminishing contribution to the overall aggregate composition estimate. In the pie charts, proteins with at least $3 \%$ intensity contribution are listed.

\section{Statistical analysis}

Statistical analysis of the MS data is described in the previous section. Statistical analysis of other data was performed using Origin Pro 2015G or GraphPad Prism 6. Data are presented as means \pm SD unless indicated otherwise.

\section{Data Availability}

The MS data from this publication are provided as supplemental tables. Raw data have been deposited to the PRIDE database (http://www.ebi.ac.uk/pride) and assigned the identifier PXD029689.

\section{Supplementary Information}

Supplementary Information is available at https://doi.org/10.26508/lsa. 202101185.

\section{Acknowledgements}

We thank F Ulrich Hartl, Mark S Hipp, Massimiliano Stagi, Georg HH Borner, and Shivani Tiwary for helpful discussions; Günter Pfeifer, Jürgen Plitzko, and Miroslava Schaffer for electron microscopy support; Qiang Guo for ribosome template matching; Andrew A Peden, F Ulrich Hartl, Mark S Hipp, Patricia Yuste-Checa, and Victoria A Trinkaus for sharing cell lines, plasmids, and reagents; Alexandra Lepier, Pontus Klein, Dieter Edbauer, and Carina Lehmer for lentiviral plasmids and generous help with lentivirus generation; Martin Dodel for excellent technical assistance; and Daniel del Toro Ruiz for kind help with image analysis. This work was funded by the European Research Council (ERC) Synergy Grant under FP7 GA number ERC-2012-SyG_318987Toxic Protein Aggregation in Neurodegeneration (ToPAG) (to M Mann, W Baumeister, and R Klein); ERC Starting Grant MitoPexLysoNETWORK 337327 (to N Raimundo); Deutsche Forschungsgemeinschaft (DFG, German Research Foundation) through Germany's Excellence Strategy - EXC 2067/1-390729940 (to R Fernández-Busnadiego); DFG Project-ID 408885537 (TRR 274) (to F Meissner); the Horst Kübler-Stiftung (to I Dudanova); and by the Max Planck Society for the Advancement of Science.

\section{Author Contributions}

I Riera-Tur: formal analysis, investigation, and visualization. T Schaefer: formal analysis, investigation, and visualization. D Hornburg: formal analysis, investigation, and visualization. A Mishra: formal analysis and investigation.

M da Silva Padilha: formal analysis, investigation, and visualization.

L Fernández-Mosquera: formal analysis and investigation.

D Feigenbutz: investigation.

P Auer: investigation.

M Mann: conceptualization, supervision, and funding acquisition. W Baumeister: conceptualization, supervision, and funding acquisition.

R Klein: conceptualization, supervision, and funding acquisition. 
F Meissner: conceptualization, supervision, and project administration. N Raimundo: conceptualization and supervision.

R Fernández-Busnadiego: conceptualization, supervision, project administration, and writing-original draft, review, and editing. I Dudanova: conceptualization, supervision, visualization, project administration, and writing-original draft, review, and editing.

\section{Conflict of Interest Statement}

The authors declare that they have no conflict of interest.

\section{References}

Abeliovich A, Gitler AD (2016) Defects in trafficking bridge Parkinson's disease pathology and genetics. Nature 539: 207-216. doi:10.1038/ nature20414

Abraham R, Hendy R, Grasso P (1968) Formation of myeloid bodies in rat liver lysosomes after chloroquine administration. Exp Mol Pathol 9: 212-229. doi:10.1016/0014-4800(68)90037-3

Armstrong L, Biancheri R, Shyr C, Rossi A, Sinclair G, Ross CJ, Tarailo-Graovac M, Wasserman WW, van Karnebeek CD (2014) AIMP1 deficiency presents as a cortical neurodegenerative disease with infantile onset. Neurogenetics 15: 157-159. doi:10.1007/s10048-014-0411-3

Arrasate M, Finkbeiner S (2012) Protein aggregates in Huntington's disease. Exp Neurol 238: 1-11. doi:10.1016/j.expneurol.2011.12.013

Bäuerlein FJB, Saha I, Mishra A, Kalemanov M, Martínez-Sánchez A, Klein R, Dudanova I, Hipp MS, Hartl FU, Baumeister W, et al (2017) In situ architecture and cellular interactions of polyQ inclusions. Cell 171: 179-187.e10. doi:10.1016/j.cell.2017.08.009

Bolte S, Cordelières FP (2006) A guided tour into subcellular colocalization analysis in light microscopy. J Microsc 224: 213-232. doi:10.1111/j.13652818.2006.01706.x

Brothers HM, Gosztyla ML, Robinson SR (2018) The physiological roles of amyloid- $\beta$ peptide hint at new ways to treat Alzheimer's disease. Front Aging Neurosci 10: 118. doi:10.3389/fnagi.2018.00118

Chiti F, Dobson CM (2017) Protein misfolding, amyloid formation, and human disease: A summary of progress over the last decade. Annu Rev Biochem 86: 27-68. doi:10.1146/annurev-biochem-061516-045115

Chu Y, Dodiya H, Aebischer P, Olanow CW, Kordower JH (2009) Alterations in lysosomal and proteasomal markers in Parkinson's disease: Relationship to alpha-synuclein inclusions. Neurobiol Dis 35: 385-398. doi:10.1016/j.nbd.2009.05.023

Cortes CJ, Miranda HC, Frankowski H, Batlevi Y, Young JE, Le A, Ivanov N, Sopher BL, Carromeu C, Muotri AR, et al (2014) Polyglutamineexpanded androgen receptor interferes with TFEB to elicit autophagy defects in SBMA. Nat Neurosci 17: 1180-1189. doi:10.1038/nn.3787

Cox J, Mann M (2008) MaxQuant enables high peptide identification rates, individualized p.p.b.-range mass accuracies and proteome-wide protein quantification. Nat Biotechnol 26: 1367-1372. doi:10.1038/ nbt.1511

Cox J, Neuhauser N, Michalski A, Scheltema RA, Olsen JV, Mann M (2011) Andromeda: A peptide search engine integrated into the MaxQuant environment. J Proteome Res 10: 1794-1805. doi:10.1021/pr101065j

Crews L, Spencer B, Desplats P, Patrick C, Paulino A, Rockenstein E, Hansen L, Adame A, Galasko D, Masliah E (2010) Selective molecular alterations in the autophagy pathway in patients with Lewy body disease and in models of alpha-synucleinopathy. PLoS One 5: e9313. doi:10.1371/ journal.pone.0009313
Crowther RA, Olesen OF, Jakes R, Goedert M (1992) The microtubule binding repeats of tau protein assemble into filaments like those found in Alzheimer's disease. FEBS Lett 309: 199-202. doi:10.1016/0014-5793(92) 81094-3

Cuervo AM, Stefanis L, Fredenburg R, Lansbury PT, Sulzer D (2004) Impaired degradation of mutant alpha-synuclein by chaperone-mediated autophagy. Science 305: 1292-1295. doi:10.1126/science.1101738

Danev R, Buijsse B, Khoshouei M, Plitzko JM, Baumeister W (2014) Volta potential phase plate for in-focus phase contrast transmission electron microscopy. Proc Natl Acad Sci U S A 111: 15635-15640. doi:10.1073/pnas.1418377111

Decressac M, Mattsson B, Weikop P, Lundblad M, Jakobsson J, Björklund A (2013) TFEB-mediated autophagy rescues midbrain dopamine neurons from $\alpha$-synuclein toxicity. Proc Natl Acad Sci U S A 110: E1817-E1826. doi:10.1073/pnas.1305623110

Dehay B, Ramirez A, Martinez-Vicente M, Perier C, Canron MH, Doudnikoff E, Vital A, Vila M, Klein C, Bezard E (2012) Loss of P-type ATPase ATP13A2/ PARK9 function induces general lysosomal deficiency and leads to Parkinson disease neurodegeneration. Proc Natl Acad Sci U S A 109: 9611-9616. doi:10.1073/pnas.1112368109

Dell'Angelica EC, Bonifacino JS (2019) Coatopathies: Genetic disorders of protein coats. Annu Rev Cell Dev Biol 35: 131-168. doi:10.1146/annurevcellbio-100818-125234

Dell'Angelica EC, Shotelersuk V, Aguilar RC, Gahl WA, Bonifacino JS (1999) Altered trafficking of lysosomal proteins in Hermansky-Pudlak syndrome due to mutations in the beta $3 \mathrm{~A}$ subunit of the AP-3 adaptor. Mol Cell 3: 11-21. doi:10.1016/s1097-2765(00)80170-7

Drummond E, Pires G, MacMurray C, Askenazi M, Nayak S, Bourdon M, Safar J, Ueberheide B, Wisniewski T (2020) Phosphorylated tau interactome in the human Alzheimer's disease brain. Brain 143: 2803-2817. doi:10.1093/brain/awaa223

Enomoto A, Asai N, Namba T, Wang Y, Kato T, Tanaka M, Tatsumi H, Taya S, Tsuboi D, Kuroda K, et al (2009) Roles of disrupted-in-schizophrenia 1interacting protein girdin in postnatal development of the dentate gyrus. Neuron 63: 774-787. doi:10.1016/j.neuron.2009.08.015

Falcon B, Zhang W, Murzin AG, Murshudov G, Garringer HJ, Vidal R, Crowther RA, Ghetti B, Scheres SHW, Goedert M (2018) Structures of filaments from Pick's disease reveal a novel tau protein fold. Nature 561: 137-140. doi:10.1038/s41586-018-0454-y

Fernandez JJ, Laugks U, Schaffer M, Bäuerlein FJ, Khoshouei M, Baumeister W, Lucic $V$ (2016) Removing contamination-induced reconstruction artifacts from cryo-electron tomograms. Biophys / 110: 850-859. doi:10.1016/j.bpj.2015.10.043

Fernández-Mosquera L, Diogo CV, Yambire KF, Santos GL, Luna Sánchez M, Bénit P, Rustin P, Lopez LC, Milosevic I, Raimundo N (2017) Acute and chronic mitochondrial respiratory chain deficiency differentially regulate lysosomal biogenesis. Sci Rep 7: 45076. doi:10.1038/srep45076

Fernandez-Mosquera L, Yambire KF, Couto R, Pereyra L, Pabis K, Ponsford AH, Diogo CV, Stagi M, Milosevic I, Raimundo N (2019) Mitochondrial respiratory chain deficiency inhibits lysosomal hydrolysis. Autophagy 15: 1572-1591. doi:10.1080/15548627.2019.1586256

Filimonenko M, Isakson P, Finley KD, Anderson M, Jeong H, Melia TJ, Bartlett BJ, Myers KM, Birkeland HC, Lamark T, et al (2010) The selective macroautophagic degradation of aggregated proteins requires the PI3P-binding protein Alfy. Mol Cell 38: 265-279. doi:10.1016/ j.molcel.2010.04.007

Finkbeiner S (2020) The autophagy lysosomal pathway and neurodegeneration. Cold Spring Harbor Perspect Biol 12: a033993. doi:10.1101/cshperspect.a033993

Finn RD, Bateman A, Clements J, Coggill P, Eberhardt RY, Eddy SR, Heger A, Hetherington K, Holm L, Mistry J, et al (2014) Pfam: The protein families database. Nucleic Acids Res 42: D222-D230. doi:10.1093/nar/gkt1223 
Fitzpatrick AWP, Falcon B, He S, Murzin AG, Murshudov G, Garringer HJ, Crowther RA, Ghetti B, Goedert M, Scheres SHW (2017) Cryo-EM structures of tau filaments from Alzheimer's disease. Nature 547: 185-190. doi:10.1038/nature23002

Fraldi A, Klein AD, Medina DL, Settembre C (2016) Brain disorders due to lysosomal dysfunction. Annu Rev Neurosci 39: 277-295. doi:10.1146/ annurev-neuro-070815-014031

Frottin F, Schueder F, Tiwary S, Gupta R, Körner R, Schlichthaerle T, Cox J, Jungmann R, Hartl FU, Hipp MS (2019) The nucleolus functions as a phase-separated protein quality control compartment. Science 365: 342-347. doi:10.1126/science.aaw9157

Glynn MW, McAllister AK (2006) Immunocytochemistry and quantification of protein colocalization in cultured neurons. Nat Protoc 1: 1287-1296. doi:10.1038/nprot.2006.220

Gowrishankar S, Yuan P, Wu Y, Schrag M, Paradise S, Grutzendler J, De Camilli P, Ferguson SM (2015) Massive accumulation of luminal proteasedeficient axonal lysosomes at Alzheimer's disease amyloid plaques. Proc Natl Acad Sci U S A 112: E3699-E3708. doi:10.1073/pnas.1510329112

Gruber A, Hornburg D, Antonin M, Krahmer N, Collado J, Schaffer M, Zubaite G, Lüchtenborg C, Sachsenheimer T, Brügger B, et al (2018) Molecular and structural architecture of polyQ aggregates in yeast. Proc Natl Acad Sci U S A 115: E3446-E3453. doi:10.1073/pnas.1717978115

Guo Q, Lehmer C, Martínez-Sánchez A, Rudack T, Beck F, Hartmann H, PérezBerlanga M, Frottin F, Hipp MS, Hartl FU, et al (2018) In situ structure of neuronal C9orf72 poly-GA aggregates reveals proteasome recruitment. Cell 172: 696-705.e12. doi:10.1016/j.cell.2017.12.030

Haass C, Selkoe DJ (2007) Soluble protein oligomers in neurodegeneration: Lessons from the Alzheimer's amyloid beta-peptide. Nat Rev Mol Cell Biol 8: 101-112. doi:10.1038/nrm2101

Harris MA, Clark J, Ireland A, Lomax J, Ashburner M, Foulger R, Eilbeck K, Lewis S, Marshall B, Mungall C, et al (2004) The Gene Ontology (GO) database and informatics resource. Nucleic Acids Res 32: D258-D261. doi:10.1093/nar/gkh036

Hartl FU (2017) Protein misfolding diseases. Annu Rev Biochem 86: 21-26. doi:10.1146/annurev-biochem-061516-044518

Hoffmann AC, Minakaki G, Menges S, Salvi R, Savitskiy S, Kazman A, Vicente Miranda H, Mielenz D, Klucken J, Winkler J, et al (2019) Extracellular aggregated alpha synuclein primarily triggers lysosomal dysfunction in neural cells prevented by trehalose. Sci Rep 9: 544. doi:10.1038/ s41598-018-35811-8

Hornburg D, Drepper C, Butter F, Meissner F, Sendtner M, Mann M (2014) Deep proteomic evaluation of primary and cell line motoneuron disease models delineates major differences in neuronal characteristics. Mol Cell Proteomics 13: 3410-3420. doi:10.1074/mcp.M113.037291

Hosp F, Gutiérrez-Ángel S, Schaefer MH, Cox J, Meissner F, Hipp MS, Hartl FU, Klein R, Dudanova I, Mann M (2017) Spatiotemporal proteomic profiling of Huntington's disease inclusions reveals widespread loss of protein function. Cell Rep 21: 2291-2303. doi:10.1016/ j.celrep.2017.10.097

Hrabe T, Chen Y, Pfeffer S, Cuellar LK, Mangold A-V, Förster F (2012) PyTom: A python-based toolbox for localization of macromolecules in cryoelectron tomograms and subtomogram analysis. J Struct Biol 178: 177-188. doi:10.1016/j.jsb.2011.12.003

Jiang M, Chen G (2006) High Ca2+-phosphate transfection efficiency in lowdensity neuronal cultures. Nat Protoc 1: 695-700. doi:10.1038/ nprot.2006.86

Jo C, Gundemir S, Pritchard S, Jin YN, Rahman I, Johnson GV (2014) Nrf2 reduces levels of phosphorylated tau protein by inducing autophagy adaptor protein NDP52. Nat Commun 5: 3496. doi:10.1038/ ncomms4496

Kantheti P, Qiao X, Diaz ME, Peden AA, Meyer GE, Carskadon SL, Kapfhamer D, Sufalko D, Robinson MS, Noebels JL, et al (1998) Mutation in AP-3 delta in the mocha mouse links endosomal transport to storage deficiency in platelets, melanosomes, and synaptic vesicles. Neuron 21: 111-122. doi:10.1016/s0896-6273(00)80519-x

Kent HM, Evans PR, Schäfer IB, Gray SR, Sanderson CM, Luzio JP, Peden AA, Owen DJ (2012) Structural basis of the intracellular sorting of the SNARE VAMP7 by the AP3 adaptor complex. Dev Cell 22: 979-988. doi:10.1016/j.devcel.2012.01.018

Khatter H, Myasnikov AG, Natchiar SK, Klaholz BP (2015) Structure of the human 80 S ribosome. Nature 520: 640-645. doi:10.1038/nature14427

Kim YE, Hosp F, Frottin F, Ge H, Mann M, Hayer-Hartl M, Hartl FU (2016) Soluble oligomers of polyQ-expanded Huntingtin target a multiplicity of key cellular factors. Mol Cell 63: 951-964. doi:10.1016/j.molcel.2016.07.022

Kremer JR, Mastronarde DN, McIntosh JR (1996) Computer visualization of three-dimensional image data using IMOD. J Struct Biol 116: 71-76. doi:10.1006/jsbi.1996.0013

Lamark T, Johansen T (2012) Aggrephagy: Selective disposal of protein aggregates by macroautophagy. Int J Cell Biol 2012: 736905. doi:10.1155/ 2012/736905

Leeman DS, Hebestreit K, Ruetz T, Webb AE, McKay A, Pollina EA, Dulken BW, Zhao X, Yeo RW, Ho TT, et al (2018) Lysosome activation clears aggregates and enhances quiescent neural stem cell activation during aging. Science 359: 1277-1283. doi:10.1126/science.aag3048

Le-Niculescu H, Niesman I, Fischer T, DeVries L, Farquhar MG (2005) Identification and characterization of GIV, a novel Galpha i/sinteracting protein found on COPI, endoplasmic reticulum-Golgi transport vesicles. J Biol Chem 280: 22012-22020. doi:10.1074/ jbc.M501833200

Li P, Merrill SA, Jorgensen EM, Shen K (2016) Two clathrin adaptor protein complexes instruct axon-dendrite polarity. Neuron 90: 564-580. doi:10.1016/j.neuron.2016.04.020

Li X, Mooney P, Zheng S, Booth CR, Braunfeld MB, Gubbens S, Agard DA, Cheng $Y$ (2013) Electron counting and beam-induced motion correction enable near-atomic-resolution single-particle cryo-EM. Nat Methods 10: 584-590. doi:10.1038/nmeth.2472

Louis JV, Martens E, Borghgraef P, Lambrecht C, Sents W, Longin S, Zwaenepoel K, Pijnenborg R, Landrieu I, Lippens G, et al (2011) Mice lacking phosphatase PP2A subunit PR61/B'delta (Ppp2r5d) develop spatially restricted tauopathy by deregulation of CDK5 and GSK3beta. Proc Natl Acad Sci U S A 108: 6957-6962. doi:10.1073/pnas.1018777108

Martinez-Sanchez A, Garcia I, Asano S, Lucic V, Fernandez JJ (2014) Robust membrane detection based on tensor voting for electron tomography. J Struct Biol 186: 49-61. doi:10.1016/j.jsb.2014.02.015

Mastronarde DN (2005) Automated electron microscope tomography using robust prediction of specimen movements. J Struct Biol 152: 36-51. doi:10.1016/j.jsb.2005.07.007

Mauthe M, Orhon I, Rocchi C, Zhou X, Luhr M, Hijlkema KJ, Coppes RP, Engedal N, Mari M, Reggiori F (2018) Chloroquine inhibits autophagic flux by decreasing autophagosome-lysosome fusion. Autophagy 14: 1435-1455. doi:10.1080/15548627.2018.1474314

May S, Hornburg D, Schludi MH, Arzberger T, Rentzsch K, Schwenk BM, Grässer FA, Mori K, Kremmer E, Banzhaf-Strathmann J, et al (2014) C9orf72 FTLD/ALS-associated Gly-Ala dipeptide repeat proteins cause neuronal toxicity and Unc119 sequestration. Acta Neuropathol 128: 485-503. doi:10.1007/s00401-014-1329-4

Mazzulli JR, Zunke F, Isacson O, Studer L, Krainc D (2016) $\alpha$-Synuclein-induced lysosomal dysfunction occurs through disruptions in protein trafficking in human midbrain synucleinopathy models. Proc Natl Acad Sci U S A 113: 1931-1936. doi:10.1073/pnas.1520335113

Menzies FM, Fleming A, Rubinsztein DC (2015) Compromised autophagy and neurodegenerative diseases. Nat Rev Neurosci 16: 345-357. doi:10.1038/nrn3961

Nakai T, Nagai T, Tanaka M, Itoh N, Asai N, Enomoto A, Asai M, Yamada S, Saifullah AB, Sokabe M, et al (2014) Girdin phosphorylation is crucial 


\section{Life Science Alliance}

for synaptic plasticity and memory: A potential role in the interaction of BDNF/TrkB/Akt signaling with NMDA receptor. J Neurosci 34: 14995-15008. doi:10.1523/JNEUROSCI.2228-14.2014

Newell-Litwa K, Seong E, Burmeister M, Faundez V (2007) Neuronal and nonneuronal functions of the AP-3 sorting machinery. J Cell Sci 120: 531-541. doi:10.1242/jcs.03365

Nixon RA (2020) The aging lysosome: An essential catalyst for late-onset neurodegenerative diseases. Biochim Biophys Acta Proteins Proteom 1868: 140443. doi:10.1016/j.bbapap.2020.140443

Nixon RA, Wegiel J, Kumar A, Yu WH, Peterhoff C, Cataldo A, Cuervo AM (2005) Extensive involvement of autophagy in Alzheimer disease: An immuno-electron microscopy study. I Neuropathol Exp Neurol 64: 113-122. doi:10.1093/jnen/64.2.113

Ohno H, Aguilar RC, Yeh D, Taura D, Saito T, Bonifacino JS (1998) The medium subunits of adaptor complexes recognize distinct but overlapping sets of tyrosine-based sorting signals. J Biol Chem 273: 25915-25921. doi:10.1074/jbc.273.40.25915

Olsen JV, Macek B, Lange O, Makarov A, Horning S, Mann M (2007) Higherenergy C-trap dissociation for peptide modification analysis. Nat Methods 4: 709-712. doi:10.1038/nmeth1060

Olzscha H, Schermann SM, Woerner AC, Pinkert S, Hecht MH, Tartaglia GG, Vendruscolo M, Hayer-Hartl M, Hartl FU, Vabulas RM (2011) Amyloidlike aggregates sequester numerous metastable proteins with essential cellular functions. Cell 144: 67-78. doi:10.1016/ j.cell.2010.11.050

Peden AA, Oorschot V, Hesser BA, Austin CD, Scheller RH, Klumperman J (2004) Localization of the AP-3 adaptor complex defines a novel endosomal exit site for lysosomal membrane proteins. J Cell Biol 164: 1065-1076. doi:10.1083/jcb.200311064

Peden AA, Rudge RE, Lui WW, Robinson MS (2002) Assembly and function of AP-3 complexes in cells expressing mutant subunits. I Cell Biol 156: 327-336. doi:10.1083/jcb.200107140

Platt FM, d'Azzo A, Davidson BL, Neufeld EF, Tifft CJ (2018) Lysosomal storage diseases. Nat Rev Dis Primers 4: 27. doi:10.1038/s41572-018-0025-4

Poole B, Ohkuma S (1981) Effect of weak bases on the intralysosomal $\mathrm{pH}$ in mouse peritoneal macrophages. J Cell Biol 90: 665-669. doi:10.1083/ jcb.90.3.665

Rigort A, Bäuerlein FJ, Leis A, Gruska M, Hoffmann C, Laugks T, Böhm U, Eibauer M, Gnaegi H, Baumeister W, et al (2010) Micromachining tools and correlative approaches for cellular cryo-electron tomography. J Struct Biol 172: 169-179. doi:10.1016/j.jsb.2010.02.011

Rigort A, Bäuerlein FJ, Villa E, Eibauer M, Laugks T, Baumeister W, Plitzko JM (2012) Focused ion beam micromachining of eukaryotic cells for cryoelectron tomography. Proc Natl Acad Sci U S A 109: 4449-4454. doi:10.1073/pnas.1201333109

Rovelet-Lecrux A, Charbonnier C, Wallon D, Nicolas G, Seaman MN, Pottier C, Breusegem SY, Mathur PP, Jenardhanan P, Le Guennec K, et al (2015) De novo deleterious genetic variations target a biological network centered on $A \beta$ peptide in early-onset Alzheimer disease. Mol Psychiatry 20: 1046-1056. doi:10.1038/mp.2015.100

Ruepp A, Waegele B, Lechner M, Brauner B, Dunger-Kaltenbach I, Fobo G, Frishman G, Montrone C, Mewes HW (2010) CORUM: The comprehensive resource of mammalian protein complexes-2009. Nucleic Acids Res 38: D497-D501. doi:10.1093/nar/gkp914

Sardiello M, Palmieri M, di Ronza A, Medina DL, Valenza M, Gennarino VA, Di Malta C, Donaudy F, Embrione V, Polishchuk RS, et al (2009) A gene network regulating lysosomal biogenesis and function. Science 325: 473-477. doi:10.1126/science.1174447

Saudou F, Humbert S (2016) The biology of Huntingtin. Neuron 89: 910-926. doi:10.1016/j.neuron.2016.02.003

Schindelin J, Arganda-Carreras I, Frise E, Kaynig V, Longair M, Pietzsch T, Preibisch S, Rueden C, Saalfeld S, Schmid B, et al (2012) Fiji: An open- source platform for biological-image analysis. Nat Methods 9: 676-682. doi:10.1038/nmeth.2019

Settembre C, Di Malta C, Polito VA, Arencibia MG, Vetrini F, Erdin S, Erdin SU, Huynh T, Medina D, Colella P, et al (2011) TFEB links autophagy to lysosomal biogenesis. Science 332: 1429-1433. doi:10.1126/ science.1204592

Settembre C, Fraldi A, Medina DL, Ballabio A (2013) Signals from the lysosome: A control centre for cellular clearance and energy metabolism. Nat Rev Mol Cell Biol 14: 283-296. doi:10.1038/nrm3565

Shirasaki DI, Greiner ER, Al-Ramahi I, Gray M, Boontheung P, Geschwind DH, Botas J, Coppola G, Horvath S, Loo JA, et al (2012) Network organization of the Huntingtin proteomic interactome in mammalian brain. Neuron 75: 41-57. doi:10.1016/j.neuron.2012.05.024

Soto C, Pritzkow S (2018) Protein misfolding, aggregation, and conformational strains in neurodegenerative diseases. Nat Neurosci 21: 1332-1340. doi:10.1038/s41593-018-0235-9

Spaet RH, Sullivan DJ, Diener RM (1983) Occurrence of myeloid bodies in rats following two-year administration of imipramine hydrochloride. Toxicol Pathol 11: 3-11. doi:10.1177/019262338301100102

Stroedicke M, Bounab Y, Strempel N, Klockmeier K, Yigit S, Friedrich RP, Chaurasia G, Li S, Hesse F, Riechers SP, et al (2015) Systematic interaction network filtering identifies CRMP1 as a novel suppressor of Huntingtin misfolding and neurotoxicity. Genome Res 25: 701-713. doi:10.1101/gr.182444.114

Suzuki K, Terry RD (1967) Fine structural localization of acid phosphatase in senile plaques in Alzheimer's presenile dementia. Acta Neuropathol 8: 276-284. doi:10.1007/BF00688828

Swank RT, Reddington M, Howlett O, Novak EK (1991) Platelet storage pool deficiency associated with inherited abnormalities of the inner ear in the mouse pigment mutants muted and mocha. Blood 78: 2036-2044. doi:10.1182/blood.v78.8.2036.bloodjournal7882036

Taylor JP, Brown RH Jr., Cleveland DW (2016) Decoding ALS: From genes to mechanism. Nature 539: 197-206. doi:10.1038/nature20413

Trinkaus VA, Riera-Tur I, Martínez-Sánchez A, Bäuerlein FJB, Guo Q, Arzberger T, Baumeister W, Dudanova I, Hipp MS, Hartl FU, et al (2021) In situ architecture of neuronal $\alpha$-Synuclein inclusions. Nat Commun 12: 2110. doi:10.1038/s41467-021-22108-0

Usenovic M, Tresse E, Mazzulli JR, Taylor JP, Krainc D (2012) Deficiency of ATP13A2 leads to lysosomal dysfunction, $\alpha$-synuclein accumulation, and neurotoxicity. J Neurosci 32: 4240-4246. doi:10.1523/ JNEUROSCI.5575-11.2012

Vincenz-Donnelly L, Holthusen H, Körner R, Hansen EC, Presto J, Johansson J, Sawarkar R, Hartl FU, Hipp MS (2018) High capacity of the endoplasmic reticulum to prevent secretion and aggregation of amyloidogenic proteins. EMBO / 37: 337-350. doi:10.15252/embj.201695841

Wagner J, Schaffer M, Fernández-Busnadiego R (2017) Cryo-electron tomography-the cell biology that came in from the cold. FEBS Lett 591: 2520-2533. doi:10.1002/1873-3468.12757

Wang C, Telpoukhovskaia MA, Bahr BA, Chen X, Gan L (2018) Endo-lysosomal dysfunction: A converging mechanism in neurodegenerative diseases. Curr Opin Neurobiol 48: 52-58. doi:10.1016/j.conb.2017.09.005

Wei Y, Liu T, Sazinsky SL, Moffet DA, Pelczer I, Hecht MH (2003) Stably folded de novo proteins from a designed combinatorial library. Protein Sci 12: 92-102. doi:10.1110/ps.0228003

West MW, Wang W, Patterson J, Mancias JD, Beasley JR, Hecht MH (1999) De novo amyloid proteins from designed combinatorial libraries. Proc Natl Acad Sci U S A 96: 11211-11216. doi:10.1073/pnas.96.20.11211

Winklhofer KF, Tatzelt J, Haass C (2008) The two faces of protein misfolding: Gain- and loss-of-function in neurodegenerative diseases. EMBO J 27: 336-349. doi:10.1038/sj.emboj.7601930

Winner B, Jappelli R, Maji SK, Desplats PA, Boyer L, Aigner S, Hetzer C, Loher T, Vilar M, Campioni S, et al (2011) In vivo demonstration that alpha- 
synuclein oligomers are toxic. Proc Natl Acad Sci U S A 108: 4194-4199. doi:10.1073/pnas.1100976108

Winslow AR, Chen CW, Corrochano S, Acevedo-Arozena A, Gordon DE, Peden AA, Lichtenberg M, Menzies FM, Ravikumar B, Imarisio S, et al (2010) $\alpha$-Synuclein impairs macroautophagy: Implications for Parkinson's disease. J Cell Biol 190: 1023-1037. doi:10.1083/ jcb.201003122

Woerner AC, Frottin F, Hornburg D, Feng LR, Meissner F, Patra M, Tatzelt J, Mann M, Winklhofer KF, Hartl FU, et al (2016) Cytoplasmic protein aggregates interfere with nucleocytoplasmic transport of protein and RNA. Science 351: 173-176. doi:10.1126/science.aad2033

Wong YC, Holzbaur EL (2014) The regulation of autophagosome dynamics by Huntingtin and HAP1 is disrupted by expression of mutant Huntingtin, leading to defective cargo degradation. J Neurosci 34: 1293-1305. doi:10.1523/JNEUROSCI.1870-13.2014

Yamamoto A, Yue Z (2014) Autophagy and its normal and pathogenic states in the brain. Annu Rev Neurosci 37: 55-78. doi:10.1146/annurev-neuro071013-014149

Yamashita N, Goshima Y (2012) Collapsin response mediator proteins regulate neuronal development and plasticity by switching their phosphorylation status. Mol Neurobiol 45: 234-246. doi:10.1007/ s12035-012-8242-4
Yang H, Hu HY (2016) Sequestration of cellular interacting partners by protein aggregates: Implication in a loss-of-function pathology. FEBS / 283: 3705-3717. doi:10.1111/febs.13722

Yuste-Checa P, Trinkaus VA, Riera-Tur I, Imamoglu R, Schaller TF, Wang H, Dudanova I, Hipp MS, Bracher A, Hartl FU (2021) The extracellular chaperone Clusterin enhances Tau aggregate seeding in a cellular model. Nat Commun 12: 4863. doi:10.1038/s41467-021-25060-1

Zhang W, Tarutani A, Newell KL, Murzin AG, Matsubara T, Falcon B, Vidal R, Garringer HJ, Shi Y, Ikeuchi T, et al (2020) Novel tau filament fold in corticobasal degeneration. Nature 580: 283-287. doi:10.1038/s41586020-2043-0

Zhou C, Slaughter BD, Unruh JR, Guo F, Yu Z, Mickey K, Narkar A, Ross RT, McClain M, Li R (2014) Organelle-based aggregation and retention of damaged proteins in asymmetrically dividing cells. Cell 159: 530-542. doi:10.1016/j.cell.2014.09.026

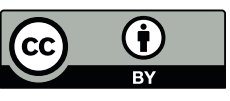

License: This article is available under a Creative Commons License (Attribution 4.0 International, as described at https://creativecommons.org/ licenses/by/4.0/). 